\title{
Pharmacology of Acid-Sensing Ion Channels- Physiological and Therapeutical perspectives
}

\author{
Anne Baron $^{\mathrm{abc}^{*}}$ \& Eric Lingueglia ${ }^{\mathrm{abc}}$

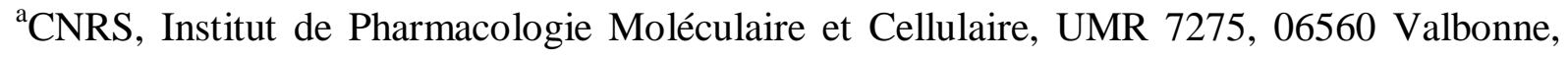 \\ France \\ ${ }^{\mathrm{b}}$ Université de Nice-Sophia Antipolis, 06560 Valbonne, France \\ ${ }^{c}$ LabEx Ion Channel Science and Therapeutics, 06560 Valbonne, France. \\ *: anne.baron@ipmc.cnrs.fr
}

\begin{abstract}
Development of the pharmacology of Acid-Sensing Ion Channels (ASICs) has become a key challenge to study their structure, their molecular and cellular functions and their physiopathological roles. This review provides a summary of the different compounds that directly interact with these channels, either with inhibitory or stimulatory effect, and with high selectivity or poor specificity. They include drugs and endogenous regulators, natural compounds of vegetal origin, and peptides isolated from animal venoms. The in vivo use of some of these pharmacological modulators in animal models and a few small clinical studies in humans have provided substantial data on the physiological and physiopathological roles of ASIC channels. Modulation of these channels will certainly provides new therapeutic opportunities in neurological and psychiatric diseases including pain, stroke, epilepsy, anxiety, depression or traumatic injury, as well as in some non-neurological pathologies.
\end{abstract}

\section{Introduction}

ASIC channels are voltage-insensitive, proton-gated cation channels activated by extracellular acidosis (Waldmann et al., 1997b). They belong to the ENaC (Epithelial $\mathrm{Na}^{+}$ Channel)/DEG (Degenerin)/ASIC (Acid-sensing ion channel) superfamily of ion channels, which share the same topology of their subunits (two transmembrane domains, a large extracellular loop, and short intracellular $\mathrm{N}$ and $\mathrm{C}$ - termini), and form amiloride-sensitive cation channels. In rodents, four genes encode at least six different ASIC subunits, ASIC1a, ASIC1b, ASIC2a, ASIC2b, ASIC3, and ASIC4. These subunits are highly expressed in neurons, but also in several non-neuronal tissues. ASIC1a and ASIC2 (both variants a and b) 
are primarily expressed in the central nervous system, while almost all subunits (except ASIC4) are expressed in sensory neurons of the peripheral nervous system(Noël et al., 2010).

Crystallization by the group of Eric Gouaux of the ASIC1a channel from chicken (Jasti et al., 2007) has shown that three subunits are required to form a functional channel that can be either homo- or heteromeric. Interestingly, it has been shown recently that the recombinant ASIC1a and ASIC2a subunits can assemble with a flexible stochiometry, i.e., no preference for homo- or heteromeric combination of subunits (Bartoi et al., 2014). ASIC2b and ASIC4 are not forming functional proton-gated channels on their own but can contribute to heteromeric channels with other ASIC subunits to modulate, at least for ASIC2b, the properties and the regulation of the channels (Noël et al., 2010). Based on the chicken ASIC1a structure, a model has been proposed where each subunit is represented as a hand holding a ball and divided into finger, thumb, palm, knuckle, $\beta$-ball, wrist, and forearm as the transmembrane domains TM1 and TM2. An "acidic pocket" containing several pairs of acidic amino acids is present at the interface between two subunits and has been proposed to be one of the pH-sensor of ASIC channels, whereas cations may access the ion channel by lateral fenestrations in the wrist region, then moving into a broad extracellular vestibule (Gonzales et al., 2009; Jasti et al., 2007) (Fig. 1).

The pharmacology of ASIC channels is diverse and has significantly increased in recent years, including synthetic compounds (Table 1), endogenous regulators (Table 2), natural products from plants and animals (Table 3), either with inhibitory or stimulatory effect and of high or poor selectivity.

\section{1-Pharmacology}

\section{1-Synthetic compounds}

\subsection{1-Amiloride and its derivatives}

Amiloride, a $\mathrm{K}^{+}$-sparing diuretic currently licensed for hypertension and heart failure, was the first blocker of ASIC channels to be described (Waldmann et al., 1997a; Waldmann et al., 1997b; Waldmann et al., 1996). Amiloride acts as a non-discriminative low affinity poreblocker of ASIC channels ( $\mathrm{IC}_{50}$ between 5 and $100 \mu \mathrm{M}$ ), but also blocks other ionic channels and exchangers (Frelin et al., 1988; Kleyman and Cragoe, 1988). Interestingly, the sustainedcomponent of the ASIC3 current is resistant to amiloride blockade. The amiloride derivatives benzamil and EIPA are also low affinity, poorly selective, reversible blockers of ASIC channels. Structure-function studies have identified amino acids possibly implicated in the 
amiloride block and located in the second transmembrane domain on the extracellular side of the channel gate (Kellenberger et al., 2003; Schild et al., 1997). Co-crystallization of the chicken ASIC1a channel in the presence of amiloride confirmed that amiloride partially occlude the pore in the extracellular vestibule (Baconguis et al., 2014), probably blocking ion conduction by dipping the amidino group into the pore (Fig. 1). In addition to its blocking effect, amiloride has an additional paradoxical enhancing effect at high concentrations, and is able to open homomeric ASIC3 channels $\left(\mathrm{EC}_{50}\right.$ of $\left.560 \mu \mathrm{M}\right)$ and heteromeric ASIC3+ASIC1b channels at neutral $\mathrm{pH}$, and also to synergistically enhance the channel activation driven by mild acidosis (Adams et al., 1999; Li et al., 2011; Waldmann et al., 1997a; Yagi et al., 2006). This activating effect, contrary to the inhibitory effect, has been shown to be dependent on the integrity of a non-proton ligand sensing domain present in ASIC3 channel ( $\mathrm{Li}$ et al., 2011). However, two molecules of amiloride were found within the acidic pocket of ASIC1a after co-crystallization of the drug with the channel, suggesting the possibility that binding of amiloride to the acidic pocket could also be involved in its paradoxical activating effect (Baconguis et al., 2014; Yu et al., 2011) (Fig. 1).

\subsection{2-GMQ}

A set of small molecules inspired from amiloride and containing a guanidinium group and a heterocyclic ring, has been also shown to activate/modulate ASIC3 channels (Yu et al., 2010), among which the synthetic GMQ (2-guanidine-4-methylquinazoline, $\mathrm{EC}_{50} \sim 1 \mathrm{mM}$,). GMQ is able to generate a current at neutral $\mathrm{pH}$ that displays little or no desensitization. The binding site of GMQ is distinct from the site involved in $\mathrm{pH}$-sensing (Yu et al., 2010; $\mathrm{Yu}$ et al., 2011) (Fig. 1) and GMQ induces an acidic shift of the $\mathrm{pH}$ dependence of inactivation of ASIC1a, ASIC1b, ASIC2a, and ASIC3 channels. It also affects the pH dependence of activation of ASIC3 channels (alkaline shift) and of ASIC1a and ASIC1b channels (acidic shift). As a consequence, GMQ creates a window current at pH 7.4 in ASIC3, but is not able to activate the other channel subtypes (Alijevic and Kellenberger, 2012). The ASIC3 channel activation was shown to be regulated by a dynamic interplay between GMQ and extracellular protons and $\mathrm{Ca}^{2}$ (Yu et al., 2010). Recently GMQ was also shown to inhibit GABA ligandgated channels with an $\mathrm{IC}_{50}$ of $0.4 \mu \mathrm{M}$ (Xiao et al., 2013).

\subsection{3-A-317567}


A-317567 is a small molecule unrelated to amiloride, which has been described to be more selective than amiloride for ASIC channels, but remains a non-discriminative inhibitor of ASIC currents ( $\mathrm{IC}_{50}: 2-30 \mu \mathrm{M}$ ) in sensory and central neurons (Coryell et al., 2009; Dube et al., 2005). The amidine moiety of A-317567 is critical for the inhibitory effect on ASIC3 current. A more potent analog was created that inhibits recombinant human ASIC3 and ASIC1a currents with a better potency ( $\mathrm{IC}_{50} \sim 356$ and $450 \mathrm{nM}$, respectively) (Kuduk et al., 2010). Unlike amiloride, A-317567 blocks both the fast and sustained phases of the ASIC3 current with equal potency. However, this compound also interacts $\left(\mathrm{IC}_{50}<10 \mu \mathrm{M}\right)$ with a number of neurotransmitter receptors, suggesting possible off-target effects if used in vivo (Kuduk et al., 2010).

\subsection{4-Non-steroid anti-inflammatory drugs}

Besides their well-known ability to inhibit cyclooxygeneases, Non-steroid antiinflammatory drugs (NSAIDs) also directly inhibit the activity of both ASIC1a and ASIC3 channels (Voilley et al., 2001)\}(Voilley, 2004). Whereas ASIC1a is inhibited by flurbiprofen and ibuprofen $\left(\mathrm{IC}_{50} \sim 350 \mu \mathrm{M}\right)$, the sustained current of ASIC3 is blocked by salicylic acid, aspirin and diclofenac $\left(\mathrm{IC}_{50}: 90-260 \mu \mathrm{M}\right)$. ASIC2a has been also shown to be partially blocked by $500 \mu \mathrm{M}$ of diclofenac, as well as heteromeric ASIC1a+ASIC2a currents. A proposed mechanism of action is allosteric inhibition of ASIC channels by slowing down the recovery after inactivation. No competition between amiloride and diclofenac was found (Dorofeeva et al., 2008). NSAIDs were shown to inhibit ASIC currents in cultured brain neurons, thus reducing acidosis-induced membrane depolarization (Wang et al., 2012), which may indicate that central ASIC channels could be targeted by high doses of aspirin and salicylate in the therapeutic concentration range.

Recently, CHF5074, a NSAID derivative devoided of cyclooxygenase inhibitory activity but holding disease-modifying potential for the treatment of Alzheimer's disease, was shown to inhibit low $\mathrm{pH}$-evoked ASIC currents in hippocampal pyramidal neurons $\left(\mathrm{IC}_{50} \sim 50\right.$ $\mathrm{nM})$. Molecular docking simulations suggest a possible binding site in the $\beta$-ball region of ASIC1a (Mango et al., 2014) (Fig. 1).

\subsection{5-Tetraethylammonium and 4-aminopyridine}

ASIC1 $a+\operatorname{ASIC} 2(a / b)$ heteromeric channels are blocked by low millimolar concentrations of tetraethylammonium (TEA), a classic nonspecific inhibitor of voltage-gated 
$\mathrm{K}^{+}$channels $(\mathrm{Kv})$, while homomeric ASIC1a channels are not, providing therefore a pharmacological way to differentiate heteromeric ASIC1a+ASIC2b and homomeric ASIC1a channels, which have otherwise very similar biophysical properties (Sherwood et al., 2011).

4-aminopyridine (4-AP), another blocker of $\mathrm{Kv}$ channels, strongly inhibits recombinant as well as neuronal ASIC1a channels $\left(\mathrm{IC}_{50} \sim 760 \mu \mathrm{M}\right)$ and recombinant channels containing the ASIC1a, ASIC1b and ASIC2a subunits, but is less active on ASIC3containing channels (no effect on homomeric ASIC3 channels). 4-AP may block ASICs and other ENaC/DEG channels through binding into the pore, as for $\mathrm{Kv}$ channels (Boiko et al., 2013) (Fig. 1).

\subsection{6-Local Anesthetics}

Local anesthetics have multiple effects including analgesia, which is largely supported by inhibition of voltage-gated $\mathrm{Na}^{+}$channels. Some local anesthetics have been shown to also inhibit ASIC channels.

Tetracaine inhibits the peak current of ASIC3 with an $\mathrm{IC}_{50}$ of $10 \mathrm{mM}$, and also partially affects the sustained current. It also blocks the ASIC1b current, but has no effect on the ASIC2a current. In cultured mouse sensory neurons, tetracaine inhibits both the peak and the sustained ASIC currents (Leng et al., 2013).

High concentrations of lidocaine also inhibit ASIC currents in mouse cortical neurons $\left(\mathrm{IC}_{50} \sim 12 \mathrm{mM}\right)$ as well as recombinant ASIC1a, but not ASIC2a channels (Lin et al., 2011).

Propofol was recently shown to partially inhibit recombinant ASIC1a and ASIC3 currents as well as native ASIC currents in DRG neurons, leading to a decrease of acidinduced neuronal excitability (Lei et al., 2014).

\subsection{7-Others drugs}

A few other non-specific small molecule inhibitors of ASIC channels have been described, some being already used in human.

Benzothiophene methyl amine is a potent, non-amidine ASIC1a and ASIC3 inhibitor $\left(\mathrm{IC}_{50} \sim 220 \mathrm{nM}\right)$, which also binds to a number of other targets (Kuduk et al., 2011).

Streptomycin and neomycin, two clinically used aminoglycosides, were shown to partially inhibit ASIC currents in DRG neurons ( IC $\left._{50} \sim 32-44 \mu \mathrm{M}\right)$ (Garza et al., 2010) and to reduce acid-triggered action potential discharges (Mercado et al., 2014). 
The protease inhibitor nafamostat mesilate, used as anticoagulant and against pancreatitis, reversibly blocks recombinant human ASIC1a, ASIC2a and ASIC3 channels $\left(\mathrm{IC}_{50} \sim 2-70 \mu \mathrm{M}\right)$ (Ugawa et al., 2007).

Chloroquine, a widely used anti-malaria drug, has been shown to impair visual transduction by inhibition of ASIC1a channels, which are functionally expressed in the retina where they are involved in its normal activity (Ettaiche et al., 2006). Chloroquine $\left(\mathrm{IC}_{50} \sim 600\right.$ $\mu \mathrm{M})$ reduces the peak amplitude and slows down the inactivation rate of the recombinant ASIC1a current and native retinal ganglion neuron currents (Li et al., 2014a).

Finally, a class of anti-parasitic drugs, the diarylamidines (DAPI, diminazene, hydroxystibamidine and pentamidine), which are widely used against trypanosomiasis and leishmaniasis, have been shown to potently inhibit ASIC currents in hippocampal neurons $\left(\mathrm{IC}_{50} \sim 300 \mathrm{nM}-38 \mu \mathrm{M}\right)$, as well as recombinant ASIC1a, ASIC1b, ASIC2a and ASIC3 channels (Chen et al., 2010).

Computational docking simulation of nafamostat and diarylamidines to the ASIC1a channel suggests that all these dicationic compounds, unlike amiloride, are probably not pore blockers but likely bind in a groove-shaped region formed by the $\beta$-ball and the palm domain, a region that partly overlaps with the binding site of the toxin PcTx1 (Chen et al., 2010) (Fig. 1).

\section{2-Endogenous modulators}

\subsection{1-Extracellular cations}

ASICs are inhibited by a variety of heavy metal ions $\left(\mathrm{Gd}^{3+}, \mathrm{Pb}^{2+}, \mathrm{Ni}^{2+}, \mathrm{Cd}^{2+}, \mathrm{Cu}^{2+}\right)$ (Allen and Attwell, 2002; Babinski et al., 2000; Sherwood et al., 2011; Staruschenko et al., 2007; Wang et al., 2006; Wang et al., 2007) and are also sensitive to bivalent cations $\left(\mathrm{Ca}^{2+}\right.$, $\mathrm{Mg}^{2+}$, and $\mathrm{Zn}^{2+}$ ) (Baron et al., 2001; Chu et al., 2004; de Weille and Bassilana, 2001; Jiang et al., 2010; Poirot et al., 2006; Waldmann et al., 1997b).

Both the ASIC1a and ASIC2a single-channel conductances are reduced by elevated levels of extracellular $\mathrm{Ca}^{2+}$ (de Weille and Bassilana, 2001). Extracellular $\mathrm{Ca}^{2+}$ modulates the apparent $\mathrm{H}^{+}$affinity for ASIC1 and the acidic pocket in the closed state of the channel may contain a $\mathrm{Ca}^{2+}$ ion that could be displaced upon acidification (Jasti et al., 2007; Paukert et al., 2008) (Fig. 1). $\mathrm{Ca}^{2+}$ ions have also been shown to bind to a high-affinity site on the extracellular side of the ASIC3 pore to block permeation of the channel (Immke and McCleskey, 2001b, 2003). The site has also been identified in ASIC1a channel, at the 
beginning of the second transmembrane domain, and $\mathrm{Ca}^{2+}$ inhibits the channel in the open state $\left(\mathrm{IC}_{50}=3.9 \mathrm{mM}\right.$ at $\left.\mathrm{pH} 5.5\right)$ with a better affinity than for $\mathrm{ASIC} 1 \mathrm{~b}\left(\mathrm{IC}_{50} \sim 10 \mathrm{mM}\right.$ at $\mathrm{pH}$ 4.7) (Paukert et al., 2004). As $\mathrm{Ca}^{2+}$ reduce the apparent affinity for amiloride, this supports a competition between $\mathrm{Ca}^{2+}$ and amiloride at the entrance of the ion pore (Paukert et al., 2004). The effect of $\mathrm{Mg}^{2+}$ on ASIC channels is comparable to that of $\mathrm{Ca}^{2+}$ (Immke and McCleskey, 2003) (Babini et al., 2002). $\mathrm{Cu}^{2+}$, the third most abundant trace element in human body, inhibits ASIC currents in central neurons with an $\mathrm{IC}_{50}$ in the $\mu \mathrm{M}$ range (Wang et al., 2007), and the neurotoxic metal ion $\mathrm{Pb}^{2+}$ strongly blocks ASIC1a-containing channels $\left(\mathrm{IC}_{50}=5 \mu \mathrm{M}\right)$ (Wang et al., 2006).

Interestingly, extracellular $\mathrm{Zn}^{2+}$ has a dual effect on ASIC channels when coapplied with acidic $\mathrm{pH}:$ a potentiating effect at micromolar concentrations $\left(\mathrm{EC}_{50} \sim 120 \mu \mathrm{M}\right)$ on ASIC2a-containing channels (Baron et al., 2001), and an inhibitory effect at nanomolar concentrations $\left(\mathrm{IC}_{50} \sim 10 \mathrm{nM}\right)$ on both homomeric ASIC1a and heteromeric ASIC1a+ASIC2a channels (Chu et al., 2004). High concentration of $\mathrm{Zn}^{2+}\left(\mathrm{IC}_{50} \sim 61 \mu \mathrm{M}\right)$ has also been reported to inhibit ASIC3 currents (Jiang et al., 2010; Poirot et al., 2006). Homomeric ASIC1b current is not inhibited by a co-application of zinc with acidic solution but is suppressed by preapplied zinc (at pH 7.4) with an $\mathrm{IC}_{50}$ of $26 \mu \mathrm{M}$ (Jiang et al., 2011; Poirot et al., 2006). $\mathrm{Zn}^{2+}$ was shown to potentiate the ASIC currents of rat hippocampal neurons (Baron et al., 2002) and of mouse dorsal spinal cord neurons (Baron et al., 2008). Very recently, ASIC excitatory post-synaptic currents were recorded for the first time in central neurons, which are triggered by synaptic acidification (Du et al., 2014; Kreple et al., 2014). Synaptically released $\mathrm{Zn}^{2+}$ could therefore target post-synaptic ASIC channels and modulate neuronal excitability or synaptic plasticity in the CNS.

Chelation of extracellular divalent cations by lactic acid produced by anaerobic metabolism during cardiac ischemia, muscular exercise or metabolic acidosis, was shown to potentiate ASIC current amplitude in response to acidosis (Immke and McCleskey, 2001a, b).

Interestingly, ammonium ions $\left(\mathrm{NH}^{+}\right)$were described to open ASIC1a channels independently of changes in proton concentration (Pidoplichko and Dani, 2006). Observation that $\mathrm{NH}_{4}^{+}$is able to induce long-lasting currents that can produce prolonged depolarization and neuronal firing in mouse mid-brain dopaminergic neurons suggests a possible contribution of ammonium-gated ASIC currents to toxicity during disorders associated with elevated ammonia. 


\subsection{2-Polyamines}

Synthetic GMQ is an activator/modulator of ASIC3 channels (see paragraph 1.1.2). The related endogenous polyamine agmatine and its analog arcaine, an inhibitor of NMDA receptors, are also able to activate homomeric ASIC3 channels and heteromeric ASIC3+ASIC1b channels $\left(\mathrm{EC}_{50} \sim 10 \mathrm{mM}\right.$ and $1.2 \mathrm{mM}$, respectively) through direct interaction with the non-proton binding domain ( $\mathrm{Li}$ et al., 2010; Yu et al., 2010) (Fig. 1). These data suggest that natural ligands beyond protons may activate ASIC channels under physiological or pathological conditions independently of a drop in $\mathrm{pH}$. Agmatine is an arginine metabolite implicated in inflammation and pain signaling, infection and cancer. It is not clear whether endogenous polyamines would reach the high levels necessary to activate ASIC3 channels, but agmatine is able to cooperate with other inflammatory signals to cause pain-related behaviors in an ASIC3-dependent manner (Li et al., 2010), suggesting that much lower concentrations could be actually necessary if co-applied with other ASIC3 modulators. Furthermore, polyamines are also known to accumulate in synaptic and dense core vesicles, raising the possibility that these molecules might also activate ASIC3 during synaptic activity (Yu et al., 2010).

Spermine, a polyvalent cation agonist of NMDA receptors, also increases ASIC1a, ASIC1b, and ASIC1a+ASIC2a currents by shifting their $\mathrm{pH}$ dependence of inactivation (Babini et al., 2002; Duan et al., 2011). It increases ASIC currents in rat hippocampal neurons with an $\mathrm{EC}_{50}$ of $495 \mathrm{nM}$ (Duan et al., 2011). The effect of spermine on ASIC channels in the central nervous system could be responsible for its neurotoxicity during brain ischemia.

\subsection{3-Neuropeptides}

FMRFamide and related peptides are direct activators of the invertebrate FMRFamidegated $\mathrm{Na}^{+}$channel (FaNaC) (Lingueglia et al., 1995; Lingueglia et al., 2006) and of HydraRFamide-gated $\mathrm{Na}^{+}$channels (HyNaC) (Durrnagel et al., 2010; Golubovic et al., 2007), two members of the ENaC/DEG/ASIC superfamily of ion channels. FMRFamide and RFamiderelated peptides, such as FRRFamide, or their mammalian relatives neuropeptide FF (NPFF, FLFQPQRFamide) and neuropeptide SF (NPSF, SLAAPQRFamide), are not direct agonists of ASIC channels but potentiate $\mathrm{H}^{+}$-gated current of recombinant ASIC1a and ASIC3 channels $\left(\mathrm{EC}_{50} \sim 10-50 \mu \mathrm{M}\right.$ ) (Askwith et al., 2000; Catarsi et al., 2001; Chen et al., 2006; Deval et al., 2003; Sherwood and Askwith, 2008), the effects being more pronounced on ASIC3 currents (Lingueglia et al., 2006). FMRFamide and related peptides act directly on the 
channel (Askwith et al., 2000; Deval et al., 2003) to increase the peak current and/or to slow down the inactivation rate, which induces or increases the sustained phase during acidification. The positive modulation of ASIC-mediated sustained depolarization by RFamide-related peptides could play a role in regulating nociceptor excitability under inflammatory conditions (Deval et al., 2003). Regions of the extracellular palm domain and the $\beta 11-12$ linker, belonging to the central vestibule, and important for inactivation and steady-state desensitization of ASIC1a have been suggested to be involved in the FRRFamide potentiating effect (Frey et al., 2013) (Fig. 1).

Two endogenous opioid neuropeptides, dynorphin A and big dynorphin, have also been shown to directly bind to ASIC1a ( $\mathrm{EC}_{50} 33$ and $26 \mathrm{nM}$, respectively) to enhance channel activity by preventing steady-state desensitization. Big dynorphin also enhances ASIC1b current. The binding site for dynorphin may overlap with the binding site of the spider toxin PcTx1 (Sherwood and Askwith, 2009).

\subsection{4-Serotonin}

Serotonin (5-HT), an inflammatory mediator known to enhance pain sensation by sensory neurons that also acts as a central neurotransmitter, increases the ASIC3-sustained current $\left(\mathrm{EC}_{50} \sim 41 \mu \mathrm{M}\right)$ but not the transient current in homomeric but not heteromeric channels. This effect does not involve activation of 5-HT receptors, but depends on the direct binding in the non-proton ligand sensing domain of ASIC3 (Wang et al., 2013) (Fig. 1). It should be noted that serotonin also acts on ASIC3-containing channels in sensory neurons through an indirect intracellular signaling pathway involving protein kinase $\mathrm{C}$ (Deval et al., 2004; Qiu et al., 2012)

\subsection{5-Arachidonic acid and lipids}

Arachidonic acid (AA), a major metabolite of membrane phospholipids, was shown to potentiate, probably through a direct effect, $\mathrm{H}^{+}$-gated ASIC currents in sensory and central neurons, as well as the currents associated with recombinant ASIC1a, ASIC2a and ASIC3 channels (concentration range 1-10 $\mu \mathrm{M}$ ) (Allen and Attwell, 2002; Deval et al., 2008; Smith et al., 2007). The endogenous cannabinoid anandamide $(5 \mu \mathrm{M})$, which has the same lipid tail than AA, potentiates ASIC1a currents on a similar way (Smith et al., 2007). The potent effect of AA on the ASIC3 current essentially results from a shift of the $\mathrm{pH}$ dependent activation towards less acidic values, which increases the window current at $\mathrm{pH}$ values close to 
physiological pH 7.4 (Deval et al., 2008). AA is thus able to interact with other molecular signals produced during inflammation to increase the ASIC3 currents and the associated pain (Deval et al., 2008).

\subsection{6-Nitric oxide}

Nitric oxyde (NO) is a short-lived, plasma membrane diffusible mediator whose release is strongly potentiated by inflammation (Eisenhut and Wallace, 2011). Nitric oxide donors potentiate both recombinant ASIC1a, ASIC1b, ASIC2b and ASIC3 currents and rat sensory neuron ASIC currents by a direct S-nitrosylation of cysteine residues located in the extracellular loop of the channel (Cadiou et al., 2007). In central nervous system, NO was shown to promote neuronal death by potentiating ASIC currents during mild and moderate acidosis (Jetti et al., 2010), which may for instance occur during ischemia.

\section{3-Natural compounds}

\subsection{1- Natural compounds of vegetal origin}

Several natural products of vegetal origin have been shown to inhibit the activity of ASIC channels. Most of them are products that are used in traditional Chinese medicines, and it will be interesting to evaluate to what extent ASIC channels contribute to their therapeutic effects in vivo.

Sevanol, a lignan from armenian thyme (Thymus armeniacus) was identified as an inhibitor of both the transient and the sustained current of recombinant human homomeric ASIC3 current $\left(\mathrm{IC}_{50} \sim 300 \mu \mathrm{M}\right)$, and also inhibits ASIC1a current with a six-fold lower affinity (Dubinnyi et al., 2012).

Chlorogenic acid, formed by the esterification of caffeic and quinic acids, is one of the most abundant polyphenols in the human diet and is found ubiquitously in plants, fruits and vegetables. In addition to its antioxidant, anti-inflammatory and neuroprotective properties, chlorogenic acid has potent analgesic properties explaining the effects of traditional medicinal plants in several countries. Chlorogenic acid was shown to inhibit native ASIC currents in rat sensory neurons $\left(\mathrm{IC}_{50} \sim 0.2 \mu \mathrm{M}\right)$ and to subsequently reduce acid-induced neuronal excitability (Qu et al., 2014).

Gastrodin is a main bioactive constituent of the traditional herbal Gastrodia elata Blume, widely used is Oriental countries for centuries as an analgesic, particularly against 
migraine and headache. Gastrodin was found to inhibit ASIC current of rat sensory neurons ( $\mathrm{IC}_{50} \sim 0.2 \mu \mathrm{M}$ ) thus reducing acid-induced neuronal excitability (Qiu et al., 2014).

Paeoniflorin is a monoterpene glycoside extracted from the root of Paeonia lactiflora, used in traditional Chinese medicine for more than 1,200 years to alleviate many inflammatory diseases and to treat neurodegenerative disorders, especially Parkinson disease. Among several other effects, it was shown to inhibit native ASIC1a current expressed by a pheochromocytoma (PC12) cell line ( $\left.\mathrm{IC}_{50} \sim 5 \mu \mathrm{M}\right)$ (Sun et al., 2011).

Puerarin is an isoflavone, the major bioactive ingredient isolated from the root of Pueraria lobata, also well known in Chinese medicine. It shows a wide spectrum of pharmacological properties such as vasodilation, cardioprotection, neuroprotection, antioxidant, anticancer, anti-inflammation, analgesia, or promoting bone formation (Zhou et al., 2013). It was shown to inhibit ASIC currents ( $\left.\mathrm{IC}_{50} \sim 38.4 \mu \mathrm{M}\right)$, and particularly ASIC1a current $\left(\mathrm{IC}_{50} \sim 9.31 \mu \mathrm{M}\right)$ in hippocampal neurons, thus preventing cells from acidosis-induced death (Gu et al., 2010).

Another flavonoid, Thalassiolin B, a sulfated flavone glycoside isolated from the sea grass Thalassia testudinum, was also shown to inhibit ASIC currents in rat sensory neurons $\left(\mathrm{IC}_{50} \sim 27 \mu \mathrm{M}\right)$ (Garateix et al., 2011).

\subsection{2-Toxins from animal venoms}

Animal venoms have been a valuable source of specific inhibitors for ASIC channels. Four main toxins have been identified from animal venoms of various origins: The spider peptide psalmotoxin-1 (PcTx1), the sea anemone peptide APETx2, the three snake peptides mambalgins and the snake heterodimeric protein MitTx. They have different, although sometimes overlapping, pharmacological profiles on the different ASIC channel subtypes (Baron et al., 2013).

\subsubsection{1-Psalmotoxin (PcTx1)}

This 40 amino-acid peptide has been isolated as a minor component (less than $1 \%$ ) of the South American tarantula Psalmopoeus cambridgei venom (Escoubas et al., 2000), folded according to the inhibitor cystine knot (ICK) motif (Escoubas et al., 2003; Saez et al., 2011). At physiological $\mathrm{pH} 7.4$, PcTx1 potently inhibit recombinant rodent $\mathrm{H}^{+}$-gated homomeric ASIC1a channels $\left(\mathrm{IC}_{50} \sim 1 \mathrm{nM}\right)$ (Escoubas et al., 2000) as well as heteromeric ASIC1a+ASIC2b channels with similar affinity (Sherwood et al., 2011), whereas it promotes 
opening of ASIC1b channels at physiological pH $7.4\left(\mathrm{EC}_{50} \sim 100 \mathrm{nM}\right)$. PcTx1 has complex state-dependent effects on ASIC1a and ASIC1b channels that depend on the pH-dependent properties of the channels (which are also different for the same channel between different animal species, e.g., rodent, chicken and human) and on the $\mathrm{pH}$ at which the toxin is applied. This leads to three different macroscopic effects that can be observed with PcTx1: inhibition of the $\mathrm{H}^{+}$-gated ASIC current, stimulation of the $\mathrm{H}^{+}$-gated ASIC current, or activation of the ASIC current at physiological pH 7.4 (Baron et al., 2013). PcTx1 effect involves principally a stabilization of the inactivated state of ASIC1a channel (Chen et al., 2005). The cocrystallisation of a chicken ASIC1a-PcTx1 complex has shown binding of PcTx1 into the acidic pocked (the pH-sensor) of ASIC1 (Fig.1) (Baconguis and Gouaux, 2012).

\subsubsection{2-APETx2}

APETx2 (42 amino acid peptide) is a minor (2\%) constituent in the venom of the sea anemone Anthopleura elegantissima (Diochot et al., 2004), belonging to the disulfide-rich all$\beta$ structural family with a fold typical of the defensin family of peptides (Chagot et al., 2005). APETx2 inhibits homomeric rat and human ASIC3 channels $\left(\mathrm{IC}_{50} \sim 37-63 \mathrm{nM}\right.$ and $\sim 175 \mathrm{nM}$, respectively), and several heteromeric ASIC3-containing channels: ASIC3+ASIC2b ( IC $_{50}$ $117 \mathrm{nM}$ ), ASIC3+ASIC1b (IC $50 \sim 0.9 \mu \mathrm{M})$ and ASIC3+ASIC1a $\left(\mathrm{IC}_{50} \sim 2 \mu \mathrm{M}\right.$ ) (Anangi et al., 2010; Chagot et al., 2005; Diochot et al., 2004; Jensen et al., 2009). APETx2 rapidly and reversibly inhibits the transient ASIC3 peak current and the sustained window current evoked at pH 7.0 (Deval et al., 2011), but the toxin does not affect the sustained component evoked at pH 5.0 (Diochot et al., 2004). However, APETx2 has been also shown to inhibit the recombinant and native Nav1.8 voltage-dependent $\mathrm{Na}^{+}$channel $\left(\mathrm{IC}_{50}\right.$ of $2.6 \mu \mathrm{M}$ for native channel in rat DRG neurons (Blanchard et al., 2012), $55 \mathrm{nM}$ for recombinant rat channel (Peigneur et al., 2012), and 6.6 - 18.7 $\mu \mathrm{M}$ for recombinant human channel (Blanchard et al., 2012; Peigneur et al., 2012)), as well as Nav1.2 ( $\left.\mathrm{IC}_{50} \sim 114 \mathrm{nM}\right)$ and Nav1.6 currents (Peigneur et al., 2012). This dual activity is not very surprising since other sea anemone peptides with the same protein scaffold are potent effectors of voltage-sensitive $\mathrm{Na}^{+}$channels (Romey et al., 1976). The binding site of APETx2 on ASIC3 is not known, but a recent computer docking simulation suggests two putative sites, the first one within the upper "thumb" area and the other one between the "wrist" and the "palm" regions, above the transmembrane helices and at the interface between adjacent subunits (Rahman and Smith, 2014) (Fig. 1). 


\subsubsection{3-MitTx}

MitTx was identified from the venom of the Texas coral snake Micrurus tener tener as a $\beta$-bungarotoxin-like structure with two non covalent subunits, a MitTx- $\alpha$ subunit consisting of a 60 amino-acid Kunitz type peptide, and a MitTx- $\beta$ subunit, which is a 120 amino-acid phospholipase A2-like protein (Bohlen et al., 2011). MitTx constitutively activates several recombinant rodent homomeric and heteromeric ASIC channels (Bohlen et al., 2011; Bohlen and Julius, 2012), particularly homomeric ASIC1a and ASIC1b (EC ${ }_{50} \sim 9$ and $23 \mathrm{nM}$, respectively), with a much lower effect on ASIC3 $\left(\mathrm{EC}_{50} \sim 830 \mathrm{nM}\right)$ and on heteromeric ASIC1a+ASIC2a channels. MitTx has only weak effects on ASIC2a current when applied at physiological $\mathrm{pH}$ 7.4, but strongly potentiates the acid-evoked current by shifting its activation curve towards less acidic $\mathrm{pH}$. The effect of MitTx on native ASIC currents in sensory trigeminal ganglion neurons seems to mainly depend on ASIC1a-containing channels because this effect disappears in neurons from ASIC1a-knockout mice (Bohlen et al., 2011). Chicken ASIC1a has been recently co-crystallized with MitTx to unveil the first physiologically relevant open structure of these channels and to address the structure of the selectivity filter (Baconguis et al., 2014). Each heterodimer of MitTx interacts almost exclusively with a single subunit by forming extensive contacts from the ion channel wrist to the knuckle and thumb domains (Fig.1). An overlap between the binding sites of PcTx1 and of the $\beta$ subunit of MitTx explains why the binding and biological activities of these two toxins are mutually exclusive (Bohlen et al., 2011). This is another nice example of how toxins targeting ASICs are important tools not only to decode the physiological roles of these channels, but also to decrypt their structural and functional features.

\subsubsection{4-Mambalgins}

Mambalgins are three 57 amino-acid peptide toxins that have been identified from the venom of the African black mamba Dendroaspis polylepis (mambalgin-1 and mambalgin-2) and from the venom of the green Mamba Dendroaspis angusticeps (mambalgin-3) (Baron et al., 2013; Diochot et al., 2012). They only differ by one residue each and define a new subfamily of three-finger toxins. Mambalgin-1, -2 and -3 display the same pharmacological properties, inhibiting recombinant homomeric rodent and human ASIC1a channels, homomeric rodent ASIC1b channels as well as other heteromeric ASIC1a-containing and ASIC1b-containing channels with $\mathrm{IC}_{50}$ ranging from 11 to $252 \mathrm{nM}$ (Baron et al., 2013). Due to 
the fact that mambalgins inhibit all ASIC channels combinations expressed in central neurons (i.e., ASIC1a, ASIC1a+2a and ASIC1a+2b), they were found to drastically inhibit the ASIC currents of spinal cord and hippocampal neurons (Baron et al., 2008; Baron et al., 2002; Diochot et al., 2012). In rat sensory neurons, mambalgins inhibit about $60 \%$ of ASIC currents and PcTx1 about 40\%, which has been attributed to the additional inhibition by mambalgins of ASIC1b-containing channels (Diochot et al., 2012). A synthetic version of mambalgin-1 potently inhibits ASIC currents recorded from human stem cell-derived sensory neurons (Young et al., 2014). Mambalgin-1 acts as a gating-modifier that binds to the closed state of the channel and induces a strong shift of the $\mathrm{pH}$-dependent activation of ASICla channel towards more acidic pH, decreasing its apparent affinity for protons (Diochot et al., 2012). The binding site and the inhibitory mechanism of mambalgin-2 on ASICla have been analyzed recently. The toxin binds into the acidic pocket of ASIC1a, showing significant overlap with the binding site of PcTx1 (Salinas et al., 2014; Schroeder et al., 2014). A model was proposed where binding of mambalgins to the upper part of the thumb domain exerts stimulatory effects but interaction with the palm domain of an adjacent subunit and with the $\beta$-ball domain trap the channel in the closed conformation by precluding the conformational changes of the palm and $\beta$-ball that follows proton activation (Salinas et al., 2014).

\subsubsection{5-Other animal toxins}

Several sea anemone toxins have been shown to inhibit ASIC channels besides APETx2.

The pi-AnmTx Ugr 9a-1 (Ugr 9-1) peptide from Urticina grebelnyi inhibits both the transient and the sustained current of recombinant human ASIC3 current. It completely blocks the transient current with an $\mathrm{IC}_{50}$ of $\sim 10 \mu \mathrm{M}$ and partially inhibits the sustained current (Osmakov et al., 2013).

PhcrTx1 from Phymanthus crucifer partially inhibits ASIC currents from sensory neurons $\left(\mathrm{IC}_{50} \sim 100 \mathrm{nM}\right.$ ) but also voltage-gated $\mathrm{K}^{+}$currents in the $\mu \mathrm{M}$ range. It presents an ICK scaffold and is the first member of a new structural group of sea anemone toxins (Rodriguez et al., 2014).

Other ASIC-targeting toxins probably exist as suggested by in vivo studies in mice showing that pain evokes by the venom of the spider Phoneutria nigriventer can be partially blocked by amiloride (Gewehr et al., 2013). 


\section{2- In vivo effects and therapeutic perspectives of ASIC-targeting compounds}

Many data on the physiological and pathological roles of ASIC channels came from pharmacological approaches using ASIC-targeting compounds in vivo in animal models as well as in some rare small clinical studies in humans (Fig. 2).

\section{1-Cutaneous analgesia}

Poorly specific ASIC blockers like amiloride, benzamil, A-317567 and related compounds have shown clear analgesic effects after in vivo local application on cutaneous pain in models of inflammatory and postoperative pain in rat (Dube et al., 2005; Kuduk et al., 2011; Kuduk et al., 2009; Rocha-Gonzalez et al., 2009). Streptomycin and neomycin, which partially inhibit ASIC currents in DRG neurons, were also shown to exert local analgesia on experimental models of inflammatory pain and GMQ-induced pain in rats (Mercado et al., 2014). All these data were supporting a role for peripheral ASIC channels in cutaneous pain, which has long remained unclear because of mixed phenotypes and/or conflicting results from studies of knockout and transgenic mice (Chen et al., 2002; Mogil et al., 2005; Page et al., 2004; Price et al., 2001; Wemmie et al., 2003; Wemmie et al., 2002), most probably because of compensatory mechanisms in these constitutive knockout animals.

The spider toxin APETx2, which blocks ASIC3-containing channels, has potent analgesic effects after local application in rodent cutaneous acidic and inflammatory pain as well as in post-operative pain, showing the important role of peripheral ASIC3 in primary thermal and mechanical hyperalgesia (Deval et al., 2011; Deval et al., 2008; Karczewski et al., 2010). The sea anemone toxin Ugr 9-1, another inhibitor of ASIC3 channels, also reversed inflammatory and acid-induced pain after intravenous injection (Osmakov et al., 2013). On the other side, pharmacological compounds that stimulate ASIC3-containing channels like GMQ (Yu et al., 2010), high concentration of amiloride ( $\mathrm{Li}$ and $\mathrm{Xu}, 2011$ ) or co-application of 5-HT and acid (Li et al., 2011; Wang et al., 2013) were shown to exert nociceptive effects.

Local peripheral application of the snake toxin MitTx, a potent activator of ASIC1 channels, strongly suggested a role for peripheral ASIC1a-containing channels in pain (Bohlen et al., 2011), while intraplantar injection of mambalgins, which inhibit ASIC1a- and ASIC1b-containing channels, provided the first demonstration of a role of DRG-specific ASIC1b-containing channels in pain (Diochot et al., 2012).

Clinical data support the involvement of ASIC channels in cutaneous acid-induced pain and inflammation associated pain in human. A decrease in $\mathrm{pH}$ in the skin of human 
volunteers has been associated with non-adapting pain (Steen et al., 1995) and this cutaneous acid-induced pain is blocked by amiloride and/or NSAIDs, with a prominent effect for $\mathrm{pH}>$ 6.0 (Jones et al., 2004; McMahon and Jones, 2004; Ugawa et al., 2002). Furthermore, topical application of a NO donor increased acid-evoked pain without affecting heat or mechanicalevoked pain (Cadiou et al., 2007). The extreme pain evoked by the Texas coral snake's venom in humans has also been attributed to the constitutive activation of human ASIC channels by the MitTx present in the venom (Bohlen et al., 2011). Interestingly, human stem cell-derived sensory neurons express different ASIC channels containing the ASIC1- and ASIC3-subunits that are sensitive to different ASIC-inhibiting toxins (Young et al., 2014).

Several vegetal extracts used in traditional Chinese medicines have been shown to target ASIC channels and have analgesic properties in human. To what extent inhibition of ASIC channels are responsible for these effects is still not completely clear but experiments in animal models are consistent with a possible contribution of ASIC channels. In mice, sevanol significantly reverses inflammatory hyperalgesia and acid-triggered visceral pain (Dubinnyi et al., 2012), thus explaining the known analgesic effects of thyme extracts. Chlorogenic acid, and Thalassiolin B alleviates inflammatory, neuropathic and visceral pain, as well as intraplantar acid-evoked pain in rats (Garateix et al., 2011; Qu et al., 2014). Finally, subcutaneous injection of gastrodin relieves chemical and acid-evoked pain in rats, without involving peripheral opioid receptors (Qiu et al., 2014).

\section{2-Muscular pain}

In a rodent model of non-inflammatory muscular pain induced by repeated acid injections into the muscle, non-selective or more specific ASIC blockers like amiloride, A317567 or APETx2 prevent the secondary mechanical hyperalgesia (i.e., the increased response to noxious stimuli outside the site of injury) (Karczewski et al., 2010; Sluka et al., 2003; Walder et al., 2010). This suggests that the chronic activation of ASIC channels (and particularly ASIC3) in muscle nociceptors is important to trigger the subsequent central sensitization contributing to secondary mechanical hyperalgesia. Local application of A317567 is also blocking pain in a model of muscle inflammation (Walder et al., 2010). Effect of A-317567 in ASIC3 knockout mice in this model also suggests the contribution of peripheral ASIC1 channels to the primary hyperalgesia in muscle inflammation.

Rescue of the ASIC3 expression in primary afferent fibers innervating muscle in ASIC3 knockout mice restores the mechanical hyperalgesia of the paw (Sluka et al., 2007), 
whereas downregulation of ASIC3 in muscular sensory fibers in wilde-type animals prevents the development of inflammatory hyperalgesia (Walder et al., 2011). Combining ASIC3 knockout mice and APETx2, the activation of ASIC3 channels were recently shown to be essential for the transition from acute to chronic pain in a mouse model of fibromyalgia induce by intramuscular acid injections (Chen et al., 2014). As the local injection of A317567 induces a reversal of muscle hyperalgesia even in ASIC3 knockout mice, it suggests that ASIC1 at the site of muscle inflammation is also important in the generation of muscle inflammation (Walder et al., 2010).

\section{2-Spinal and supra-spinal pain processing}

Intrathecal (i.t.) amiloride and benzamil injections display antinociceptive effects in the rat spinal nerve ligation model suggesting they may present an alternative pharmacological tool in the management of neuropathic pain at the spinal level (Jeong et al., 2013). In mice, i.t. and intracerebroventricular (i.c.v.) injections of the spider toxin PcTx1, a specific inhibitor of ASIC1a channels, induce potent analgesic effects in acute pain as well as in inflammatory and neuropathic pain models (Mazzuca et al., 2007) through blockade of ASIC1a homomeric channels, and probably ASIC1a+ASIC2b channels (Sherwood et al., 2011). These analgesic effects involve the release, by a yet unknown mechanism, of endogenous Met-enkephalin in the cerebrospinal fluid after inhibition of ASIC1a channels. PcTx1 (i.t.) also prevent chronic abdominal pain in a rat model of irritable bowel syndrome induced by butyrate (Matricon et al., 2011). Central injections of the snake toxins mambalgins in mice also induce potent analgesic effects in acute as well as inflammatory pain (Diochot et al., 2012), which are independent of the opioid system, contrary to the effects of PcTx1. Participation of the ASIC2a subunit in these effects via heteromeric ASIC1a+ASIC2a channels provides the first evidence of the involvement of ASIC2a in pain. Interestingly, acute inhibition of spinal and supra-spinal ASICla-containing channels by these specific toxins reveals a role for these channels in pain processing in the CNS, which was not anticipated from ASIC1a-knockout animals that have no major pain phenotype (Wemmie et al., 2003; Wemmie et al., 2002), probably because of compensatory mechanisms in these constitutive knockout mice.

\section{3-Migraine}


Amiloride (Yan et al., 2011), GMQ and APETx2 (Yan et al., 2013) analgesic effects have shown a role of peripheral ASIC3 channels expressed in dural afferents in migrainerelated behaviour. PcTx1-containing venom has been recently shown to block cortical spreading depression in rats, a phenomenon associated with migraine with aura in human (Holland et al., 2012). Interestingly, in a small clinical study amiloride shows some efficacy for the reduction of aura and headache symptoms (Holland et al., 2012).

\section{4-Articular and bone pathophysiology}

In a rat model of ostheoarthritis, continuous intra-articular administrations of APETx2 reduced pain-related behaviour and secondary hyperalgesia by local inhibition of ASIC3containing channels expressed in sensory neurons (Izumi et al., 2012). ASIC3 is expressed in joint afferent sensory neurons but also in chondrocytes and synoviocytes (Ikeuchi et al., 2009; Kolker et al., 2010), and the analgesic effects of APETx 2 were shown to be complemented by a reduction of cartilage damage caused by inflammation (Izumi et al., 2012). Similar results have been obtained with amiloride that protects articular chondrocytes from acid-induced apoptosis (Hu et al., 2012), leading to chondroprotection in arthritis rats (Yuan et al., 2010a). PcTx1-containing venom also significantly inhibits the increase in intracellular $\mathrm{Ca}^{2+}$ and the acid-induced death of cultured rat articular chondrocytes (Yuan et al., 2010b), as well as of rat endplate chondrocytes of intervertebral discs (Li et al., 2014b), suggesting that the inhibition of ASIC1a channels could also protect chondrocytes. Interestingly, an increased expression of ASIC proteins was recently described in human degenerated intervertebral discs compared to healthy tissues (Cuesta et al., 2014).

Bone homeostasis is strictly regulated by control of bone resorption by osteoclasts and bone formation by osteoblasts, and most adult skeletal diseases, such as osteoporosis, are mostly due to excess osteoclastic activity. Previous work has shown that ASIC channels are expressed at high levels in human bone cells (Jahr et al., 2005). Extracellular acidosis induces osteoclastogenesis through intracellular $\mathrm{Ca}^{2+}$ rise, and both PcTx1 and specific siRNA significantly inhibit these events leading to bone resorption (Li et al., 2013). Thus, ASIC1a channels may play a role in $\mathrm{pH}$ sensing in osteoclasts, and appear as potential therapeutic targets for the treatment of human diseases caused by excessive activity of osteoclasts, such as osteoporosis.

\section{5-Neuroprotection}


ASIC1a channels in the CNS participate to acidotoxicity and neuronal death associated with ischemia or traumatic injury (Duan et al., 2011; Xiong et al., 2004), and their inhibition have neuroprotective effects. In rodents, the i.c.v. injection of amiloride, PcTx1 or PcTx1-containing venom protects against severe focal ischemia by reducing the infarct volume by more than 50\% (Pignataro et al., 2007; Xiong et al., 2004). An intraperitoneal (i.p.) injection of flurbiprofen has a similar effect (Mishra et al., 2010). PcTx1-containing venom and amiloride also showed neuroprotective effects in animal models of ischemia produced by asphyxia-induced cardiac arrest (Tai and Truong, 2013; Yang et al., 2011). In rat spinal cord, i.t. injection of PcTx1-containing venom reduces the lesion volume induced by traumatic injury and increases locomotor recovery (Hu et al., 2011). The abundance of the endogenous polyamine spermine in the central nervous system and its interaction with ASIC channels could also have important consequences for neurotoxicity (Babini et al., 2002). The i.c.v. delivery of exogenous spermine before middle cerebral artery occlusion increases infarct volume, but this toxicity-promoting effect is significantly reduced in ASICla-knockout mice (Duan et al., 2011).

Amiloride showed neuroprotective as well as myeloprotective effects in animal models of multiple sclerosis (Friese et al., 2007; Vergo et al., 2011). Interestingly, chronic brain lesions of patients with progressive multiple sclerosis show an increased expression of ASIC1 in axons, and a recent pilot study showed that orally given amiloride could exert neuroprotective effects (Arun et al., 2013).

ASIC channels are involved in normal retinal activity (Ettaiche et al., 2006; Ettaiche et al., 2009; Ettaiche et al., 2004). Ischemic retinal ganglion cell injury plays a role in a variety of retinal diseases such as diabetic retinopathy, hypertensive vascular disease and glaucoma. PcTx1 reduced ischemia-induced cell death of cultured rat retinal ganglion cells (Tan et al., 2011), and in vivo amiloride significantly decreased ischemia-induced retinal degeneration in rats (Miyake et al., 2013).

ASIC channel inhibitors are also neuroprotective in animal models of neurodegenerative diseases. In a mouse model of Huntington's disease, depletion of ASICla or treatment with amiloride or benzamil reduced polyglutamine aggregation (Wong et al., 2008). Furthermore, both amiloride and PcTx1 are neuroprotective in a mouse model of Parkinson's disease (Arias et al., 2008), and the neuroprotective effect of paeoniflorin, the principal active ingredient of an anti-Parkinson's disease traditional Chinese medicine, may involve inhibition of ASIC1a channels (Sun et al., 2011). 


\section{6-Psychiatric disorders}

\subsection{1-Fear-related behaviours}

In mice, i.c.v. injection of PcTx1-containing venom reduces innate fear-related behaviour (Coryell et al., 2007) through inhibition of ASIC1a channels. Accordingly, ASIC1a-knockout mice show reduced innate fear, whereas restoring ASIC1a expression in the basolateral amygdala of ASIC1a-knockout mice rescues contextual fear conditioning (Coryell et al., 2008), and overexpression of ASIC1a in transgenic mice increases fear conditioning (Wemmie et al., 2004). Recently, acidification of the synaptic cleft upon physiological neuronal activity was found to activate post-synaptic ASIC currents in the lateral amygdala, which are blocked by amiloride but not by PcTx1 (Du et al., 2014), and are involved in synaptic plasticity processes underlying amygdala-dependent fear-related learning and memory.

Anxiolytic-like effects of PcTx1 have also been described. In the stress-induced hyperthermia model, i.c.v. administration of PcTx1-containing venom prevents stress-induced elevations in mice core body temperature (Dwyer et al., 2009). GABAergic mechanisms in the amygdala were proposed to mediate these anxiolytic-like effects, but the precise pathways involved are not known. Recently, a genetic variation of the human gene coding for ASICla has been associated with panic disorder and with amygdala phenotypes that have been linked to proneness to anxiety (Smoller et al., 2014).

\subsection{2-Depression}

An i.c.v. injection of PcTx1 has antidepressant effects (Coryell et al., 2009) through inhibition of ASIC1a channels. ASIC1a-knockout mice are resistant to depression, whereas restoring the expression of ASIC1a in the amygdala of ASIC1a-knockout mice eliminates the antidepressant-like phenotype. A-317567, a non-discriminative inhibitor of ASIC channels, also exerts antidepressant effects through ASIC1a blocking after i.c.v. injection (Coryell et al., 2009). These findings raise the possibility that inhibiting ASICla channels might reduce depression.

\section{7-Epilepsy}

In an in vivo model of kainate-induced epilepsy, i.c.v. injection of PcTx1 reduces both the seizure activity and the neuronal injury (Xiong et al., 2008), consistent with other studies 
showing an inhibition of seizures by amiloride in rats and mice (Ali et al., 2006; Luszczki et al., 2009; N'Gouemo, 2008; Quansah and N'Gouemo, 2014). This raises the possibility of a contribution of ASIC channels, and ASIC1a-containing channels in particular, to the generation and/or maintenance of seizures. However, other results have shown that i.c.v. injection of PcTx1-containing venom, or deletion of ASIC1a, increased seizure severity in mice, which has been associated with a protecting role of ASIC1a-containing channels in seizure termination by acidosis through an increase in the inhibitory tone of inhibitory interneurons (Ziemann et al., 2008). Further studies will certainly provide a better understanding of the different contributions of ASIC channels in epilepsy.

In humans, genetic study suggested an association between single nucleotide polymorphisms in ASIC1 and temporal lobe epilepsy (Lv et al., 2011). A down regulation of the expression of ASICla was also reported in cortical lesions of patients with focal cortical dysplasia, a well-recognized cause of medically intractable epilepsy (Guo et al., 2014), which suggest that ASICla loss may contribute to epileptogenesis in these patients.

\section{8-Inhibition of acidosis-induced hyperventilation and bradycardia}

Recent data obtained in rats also support the involvement of ASIC channels in central chemoreception and breathing control. Injection of PcTx1 in the lateral hypothalamus inhibits ASIC1a channels in orexin neurons and the orexin action on the medulla respiratory centre, which blocks the increase in breathing frequency induced by extracellular acidosis (Song et al., 2012). ASIC-containing neurons are also present in the nucleus of the solitary tract that project to respiratory centres to increase breathing frequency in hypercapnic rats (Huda et al., 2012).

Cardiorespiratory homeostasis is regulated by central $\mathrm{pH}$ sensitivity. Genetic deletion of ASIC2 leads to hypertension and increased heart rate in conscious mice, due to an enhanced sympathetic and depressed parasympathetic cardiovascular control ( $\mathrm{Lu}$ et al., 2009). In rats, pretreatment with either amiloride or benzamil abolishes the bradycardia induced by microinjection of acidic artificial cerebrospinal fluid $(\mathrm{pH}$ 6.2) into the nucleus ambiguus (Brailoiu et al., 2014), thus supporting a critical role for ASIC channels in modulating cardiac vagal parasympathetic tone and provide a potential mechanism for acidosis-induced bradycardia.

\section{9-Vascular tone control}


Amiloride and APETx2 markedly attenuate the exercise pressor reflex generated by contracting skeletal muscle (Hayes et al., 2007; McCord et al., 2009; Tsuchimochi et al., 2011). The role of ASIC channels in the local vascular control is supported by the expression of ASIC3 in muscle metaboreceptors, the sensory nerves that innervate muscle arterioles and detect changes in muscle metabolism (Molliver et al., 2005). Through inhibition of ASIC3containing channels in sensory neurons, APETx2, amiloride and diclofenac inhibit skin vasodilation response to direct pressure (pressure-induced vasodilation or PIV) in both humans and rodents (Fromy et al., 2012).

ASIC channels are also expressed in vascular smooth muscle cells from arteries (Drummond et al., 2008). In rat pulmonary arteries, PcTx1 reduces store-operated calcium entry in vascular smooth muscle cells (Jernigan et al., 2009), as well as agonist-induced vasoconstriction, agonist-induced increase in intracellular $\mathrm{Ca}^{2+}$ and the hypoxia-induced enhanced store-operated calcium entry (Jernigan et al., 2012). These results suggest that ASIC1a-containing channels could be involved in the effect of chronic hypoxia on vascular tone.

\subsection{0-Adipocytes physiology and diabetes}

ASIC3 current are expressed by adipose cells, and ASIC3-knockout mice show a lean phenotype (related to a smaller size of adipocytes), enhanced insulin sensitivity and a protection against age-dependent glucose intolerance. The i.p. injection of APETx2 in aged wild-type mice produces the same effects (Huang et al., 2008), thus supporting a role for ASIC3 in age-dependent glucose intolerance and insulin resistance in adipocytes, which may relate to their capacity to sense lactate. Indeed, elevated basal level of lactate is consistently found in diabetic subjects who also display marked insulin resistance (DiGirolamo et al., 1992).

\subsection{1- Hepatic fibrosis}

Liver fibrogenesis is a common widespread pathophysiological response to hepatitis viral infections and alcohol toxicity; amplified by a chronic inflammation. In the pathological process, protons are released by damaged cells and acidosis plays a critical role in cell injury and activation of hepatic stellate cells involved in the fibrotic cascades. Through inhibition of ASICla channels, PcTx1 was recently showed to inhibit the signs of progression of rat hepatic fibrosis ( $\mathrm{Wu}$ et al., 2014). In vivo experiments showed that amiloride could 
significantly alleviate rat liver injury, and reduce pathological tissue damage (Pan et al., 2014).

\subsection{2-Gliomas}

Grade IV gliomas are the most common and most aggressive of all brain tumors, exhibiting high rates of proliferation and migration, often setting up secondary foci distant from the primary tumor. Glioblastoma cells exhibit constitutively active amiloride- and PcTx1-sensitive ASIC currents. PcTx1 and ASIC1-silencing inhibit migration and proliferation of cultured human glioma cells. Similarly, the amiloride analogue benzamil caused cell cycle arrest (Rooj et al., 2012). These results suggest the intriguing possibility that targeting $\mathrm{pH}$ and ASICs might inhibit the growth and spread of some cancers.

\section{Conclusion}

Acid-sensing ion channels are directly modulated by a variety of compounds of synthetic, endogenous and natural origin. The best know synthetic inhibitor of ASIC channels is amiloride, which is not selective but is in clinical use and, as such, can be administered in humans. Other amiloride related and unrelated molecules can also block ASIC channels with poor channel specificity including A-317567, non-steroid anti-inflammatory drugs (NSAIDs), local anesthetics, some voltage-gated $\mathrm{K}^{+}$channel blockers like tetraethylammonium and 4aminopyridine, and a few other compounds, some in clinical use (benzothiophene methyl amine, streptomycin, neomycin, nafamostat mesilate, chloroquine and diarylamidines). Other synthetic molecules like GMQ potentiate, or even activate, ASIC channels. Direct endogenous modulators that potentiate the activity of ASIC channels include some polyamines like agmatine, arcaine or spermine, neuropeptides like RFamide-related peptides and opioid-related dynorphin A and big dynorphin, serotonin, arachidonic acid, and nitric oxide. Several extracellular cations inhibit the activity of ASICs, with the exception of $\mathrm{Zn}^{2+}$ that has a dual potentiating and inhibitory effect. Natural compounds of vegetal origin have been shown to inhibit the activity of ASIC channels, most of them being used in traditional Chinese medicines. The most selective modulators of ASIC channels are coming from animal venoms with highly selective toxins that inhibit (PcTx1, APETx2, mambalgins) and sometimes activate (MitTx) these channels.

The in vivo effects of several synthetic and/or natural pharmacological modulators of ASIC channels (mostly inhibitors), in combination with knockout or knockdown animals, has 
been successfully used to decipher the physiological and pathophysiological roles of these channels. They emerge from these studies as interesting targets for drug development in a variety of neurological and psychiatric disorders including pain, stroke, epilepsy, anxiety, depression or traumatic injury. An increasing body of data also suggests possible roles outside the nervous system (e.g., in hepatic fibrosis or osteoarthritis). Some already identified ASIC inhibitors like the specific peptides discovered in animal venoms, could therefore not only be pharmacological tools to explore the function of these channels, but also compounds of potential therapeutic value, or may alternatively represent new leads for development of therapeutically useful inhibitors of these channels. Interestingly, non-selective inhibitors of ASIC channels are actually already used in humans, many of them in traditional Chinese medicines, and it will be interesting to evaluate the contribution of ASIC channels to their therapeutic effect. A few small scale clinical studies in human using amiloride have also given encouraging data for cutaneous pain, migraine and multiple sclerosis (Arun et al., 2013; Cadiou et al., 2007; Holland et al., 2012; Jones et al., 2004; Ugawa et al., 2002). Targeting endogenous modulators of ASIC channels can also be an alternative strategy as suggested by the artificial local modulation of NO in human skin (Cadiou et al., 2007). Stimulatory compounds could also be of therapeutical interest, for example in case of epilepsy or drug addiction, as suggest by recent data showing that synaptic ASIC1a-containing channels in the nucleus accumbens inhibit the plasticity underlying addiction-related behavior in mice (Kreple et al., 2014).

The pharmacology of ASIC channels has made rapid progress the last years, and ASIC modulators have been instrumental to study the structure, the properties, the functional expression and the physiopathological roles of these channels. New therapeutic opportunities in neurological and psychiatric diseases, but also in some non-neurological pathologies, will certainly come from the inhibition (but also possibly stimulation) of these important channels. 


\section{LEGENDS}

\section{Table 1: Synthetic modulators of ASIC channels}

Activating/potentiating and inhibitory effects are indicated in red and blue, respectively. See the main text for corresponding references. All: all homomeric ASIC channels.

\section{Table 2: Endogenous modulators of ASIC channels}

Activating/potentiating and inhibitory effects are indicated in red and blue, respectively. See the main text for corresponding references. All: all homomeric ASIC channels.

\section{Table 3: Natural compounds targeting ASIC channels}

Compounds of vegetal origin and toxins from animal venoms are displayed on pink and yellow backgrounds, respectively. Activating/potentiating and inhibitory effects are indicated in red and blue, respectively. See the main text for corresponding references. All: all homomeric ASIC channels.

\section{Figure 1: Sites of interaction of the ASIC-targeting compounds}

Schematic representation of an ASIC channel based on the chicken ASIC1a structure according to the model of a hand holding a ball (Jasti et al., 2007). Only two subunits out of three are shown for clarity. The inhibitory (-) and stimulatory (+) effects of the different compounds are indicated. Psalmotoxin 1 (PcTx1) can inhibit or activate ASIC channels depending of the channel subtype and the animal species. Amiloride has different binding sites associated with its inhibitory and stimulatory effects. An interrogation mark indicates that the binding site has not been formally demonstrated, with sometimes different possibilities as for APETx2. Note that the listed compounds are not necessarily targeting the same ASIC channel subtypes (see text for details).

\section{Figure 2: In vivo effects of the ASIC-targeting compounds}

The subtypes of ASIC channels involved are shown $(-$ and + represent pharmacological inhibition and stimulation, respectively). Effects on homomeric or heteromeric channels are not distinguished. See text for details. PIV, pressure-induced vasodilation. 


\section{References}

Adams, C. M., Snyder, P. M., Welsh, M. J., 1999. Paradoxical stimulation of a DEG/ENaC channel by amiloride. J Biol Chem 274, 15500-15504.

Ali, A., Pillai, K. P., Ahmad, F. J., Dua, Y., Vohora, D., 2006. Anticonvulsant effect of amiloride in pentetrazole-induced status epilepticus in mice. Pharmacol Rep 58, 242-245.

Alijevic, O., Kellenberger, S., 2012. Subtype-specific modulation of acid-sensing ion channel (ASIC) function by 2-guanidine-4-methylquinazoline. J Biol Chem 287, 3605936070 .

Allen, N. J., Attwell, D., 2002. Modulation of ASIC channels in rat cerebellar Purkinje neurons by ischaemia-related signals. J Physiol 543, 521-529.

Anangi, R., Chen, C. C., Lin, Y. W., Cheng, Y. R., Cheng, C. H., Chen, Y. C., Chu, Y. P., Chuang, W. J., 2010. Expression in Pichia pastoris and characterization of APETx2, a specific inhibitor of acid sensing ion channel 3. Toxicon 56, 1388-1397.

Arias, R. L., Sung, M. L., Vasylyev, D., Zhang, M. Y., Albinson, K., Kubek, K., Kagan, N., Beyer, C., Lin, Q., Dwyer, J. M., Zaleska, M. M., Bowlby, M. R., Dunlop, J., Monaghan, M., 2008. Amiloride is neuroprotective in an MPTP model of Parkinson's disease. Neurobiol Dis 31, 334-341.

Arun, T., Tomassini, V., Sbardella, E., de Ruiter, M. B., Matthews, L., Leite, M. I., Gelineau-Morel, R., Cavey, A., Vergo, S., Craner, M., Fugger, L., Rovira, A., Jenkinson, M., Palace, J., 2013. Targeting ASIC1 in primary progressive multiple sclerosis: evidence of neuroprotection with amiloride. Brain 136, 106-115.

Askwith, C. C., Cheng, C., Ikuma, M., Benson, C., Price, M. P., Welsh, M. J., 2000. Neuropeptide FF and FMRFamide potentiate acid-evoked currents from sensory neurons and proton-gated DEG/ENaC channels. Neuron 26, 133-141.

Babini, E., Paukert, M., Geisler, H. S., Grunder, S., 2002. Alternative splicing and interaction with di- and polyvalent cations control the dynamic range of acid-sensing ion channel 1 (ASIC1). J Biol Chem 277, 41597-41603.

Babinski, K., Catarsi, S., Biagini, G., Seguela, P., 2000. Mammalian ASIC2a and ASIC3 subunits co-assemble into heteromeric proton- gated channels sensitive to $\mathrm{Gd}^{3+}$. Journal of Biological Chemistry 275, 28519-28525. 
Baconguis, I., Bohlen, C. J., Goehring, A., Julius, D., Gouaux, E., 2014. X-ray structure of acid-sensing ion channel 1-snake toxin complex reveals open state of a $\mathrm{Na}^{+}-$ selective channel. Cell 156, 717-729.

Baconguis, I., Gouaux, E., 2012. Structural plasticity and dynamic selectivity of acidsensing ion channel-spider toxin complexes. Nature 489, 400-405.

Baron, A., Diochot, S., Salinas, M., Deval, E., Noel, J., Lingueglia, E., 2013. Venom toxins in the exploration of molecular, physiological and pathophysiological functions of acid-sensing ion channels. Toxicon 75, 187-204.

Baron, A., Schaefer, L., Lingueglia, E., Champigny, G., Lazdunski, M., 2001. Zn ${ }^{2+}$ and $\mathrm{H}^{+}$are coactivators of acid-sensing ion channels. J Biol Chem 276, 35361-35367.

Baron, A., Voilley, N., Lazdunski, M., Lingueglia, E., 2008. Acid sensing ion channels in dorsal spinal cord neurons. J Neurosci 28, 1498-1508.

Baron, A., Waldmann, R., Lazdunski, M., 2002. ASIC-like, proton-activated currents in rat hippocampal neurons. J Physiol 539, 485-494.

Bartoi, T., Augustinowski, K., Polleichtner, G., Grunder, S., Ulbrich, M. H., 2014. Acid-sensing ion channel (ASIC) 1a/2a heteromers have a flexible 2:1/1:2 stoichiometry. Proc Natl Acad Sci U S A 111, 8281-8286.

Blanchard, M. G., Rash, L. D., Kellenberger, S., 2012. Inhibition of voltage-gated $\mathrm{Na}^{+}$ currents in sensory neurones by the sea anemone toxin APETx2. Br J Pharmacol 165, 21672177.

Bohlen, C. J., Chesler, A. T., Sharif-Naeini, R., Medzihradszky, K. F., Zhou, S., King, D., Sanchez, E. E., Burlingame, A. L., Basbaum, A. I., Julius, D., 2011. A heteromeric Texas coral snake toxin targets acid-sensing ion channels to produce pain. Nature 479, 410-414.

Bohlen, C. J., Julius, D., 2012. Receptor-targeting mechanisms of pain-causing toxins: How ow? Toxicon 60, 254-264.

Boiko, N., Kucher, V., Eaton, B. A., Stockand, J. D., 2013. Inhibition of neuronal degenerin/epithelial $\mathrm{Na}^{+}$channels by the multiple sclerosis drug 4-aminopyridine. J Biol Chem 288, 9418-9427.

Brailoiu, G. C., Deliu, E., Altmann, J. B., Chitravanshi, V., Brailoiu, E., 2014. Evidence for role of acid-sensing ion channels in nucleus ambiguus neurons: essential differences in anesthetized versus awake rats. J Comp Physiol B 184, 753-761. 
Cadiou, H., Studer, M., Jones, N. G., Smith, E. S., Ballard, A., McMahon, S. B., McNaughton, P. A., 2007. Modulation of acid-sensing ion channel activity by nitric oxide. J Neurosci 27, 13251-13260.

Catarsi, S., Babinski, K., Seguela, P., 2001. Selective modulation of heteromeric ASIC proton-gated channels by neuropeptide FF. Neuropharmacology 41, 592-600.

Chagot, B., Escoubas, P., Diochot, S., Bernard, C., Lazdunski, M., Darbon, H., 2005. Solution structure of APETx2, a specific peptide inhibitor of ASIC3 proton-gated channels. Protein Sci 14, 2003-2010.

Chen, C. C., Zimmer, A., Sun, W. H., Hall, J., Brownstein, M. J., 2002. A role for ASIC3 in the modulation of high-intensity pain stimuli. Proc Natl Acad Sci U S A 99, 89928997.

Chen, W. N., Lee, C. H., Lin, S. H., Wong, C. W., Sun, W. H., Wood, J. N., Chen, C. C., 2014. Roles of ASIC3, TRPV1, and NaV1.8 in the transition from acute to chronic pain in a mouse model of fibromyalgia. Mol Pain 10, 40.

Chen, X., Kalbacher, H., Grunder, S., 2005. The tarantula toxin psalmotoxin 1 inhibits acid-sensing ion channel (ASIC) 1a by increasing its apparent $\mathrm{H}^{+}$affinity. J Gen Physiol 126, 71-79.

Chen, X., Paukert, M., Kadurin, I., Pusch, M., Grunder, S., 2006. Strong modulation by RFamide neuropeptides of the ASIC1b/3 heteromer in competition with extracellular calcium. Neuropharmacology 50, 964-974.

Chen, X., Qiu, L., Li, M., Durrnagel, S., Orser, B. A., Xiong, Z. G., Macdonald, J. F., 2010. Diarylamidines: High potency inhibitors of acid-sensing ion channels. Neuropharmacology 58, 1045-1053.

Chu, X. P., Wemmie, J. A., Wang, W. Z., Zhu, X. M., Saugstad, J. A., Price, M. P., Simon, R. P., Xiong, Z. G., 2004. Subunit-dependent high-affinity zinc inhibition of acidsensing ion channels. J Neurosci 24, 8678-8689.

Coryell, M. W., Wunsch, A. M., Haenfler, J. M., Allen, J. E., McBride, J. L., Davidson, B. L., Wemmie, J. A., 2008. Restoring Acid-sensing ion channel-1a in the amygdala of knock-out mice rescues fear memory but not unconditioned fear responses. $\mathrm{J}$ Neurosci 28, 13738-13741.

Coryell, M. W., Wunsch, A. M., Haenfler, J. M., Allen, J. E., Schnizler, M., Ziemann, A. E., Cook, M. N., Dunning, J. P., Price, M. P., Rainier, J. D., Liu, Z., Light, A. R., 
Langbehn, D. R., Wemmie, J. A., 2009. Acid-sensing ion channel-1a in the amygdala, a novel therapeutic target in depression-related behavior. J Neurosci 29, 5381-5388.

Coryell, M. W., Ziemann, A. E., Westmoreland, P. J., Haenfler, J. M., Kurjakovic, Z., Zha, X. M., Price, M., Schnizler, M. K., Wemmie, J. A., 2007. Targeting ASIC1a reduces innate fear and alters neuronal activity in the fear circuit. Biol Psychiatry 62, 1140-1148.

Cuesta, A., Del Valle, M. E., Garcia-Suarez, O., Vina, E., Cabo, R., Vazquez, G., Cobo, J. L., Murcia, A., Alvarez-Vega, M., Garcia-Cosamalon, J., Vega, J. A., 2014. Acidsensing ion channels in healthy and degenerated human intervertebral disc. Connect Tissue Res 55, 197-204.

de Weille, J., Bassilana, F., 2001. Dependence of the acid-sensitive ion channel, ASIC1a, on extracellular $\mathrm{Ca}^{2+}$ ions. Brain Res 900, 277-281.

Deval, E., Baron, A., Lingueglia, E., Mazarguil, H., Zajac, J. M., Lazdunski, M., 2003. Effects of neuropeptide SF and related peptides on acid sensing ion channel 3 and sensory neuron excitability. Neuropharmacology 44, 662-671.

Deval, E., Noel, J., Gasull, X., Delaunay, A., Alloui, A., Friend, V., Eschalier, A., Lazdunski, M., Lingueglia, E., 2011. Acid-sensing ion channels in postoperative pain. J Neurosci 31, 6059-6066.

Deval, E., Noel, J., Lay, N., Alloui, A., Diochot, S., Friend, V., Jodar, M., Lazdunski, M., Lingueglia, E., 2008. ASIC3, a sensor of acidic and primary inflammatory pain. EMBO J 27, 3047-3055.

Deval, E., Salinas, M., Baron, A., Lingueglia, E., Lazdunski, M., 2004. ASIC2bdependent regulation of ASIC3, an essential acid-sensing ion channel subunit in sensory neurons via the partner protein PICK-1. J Biol Chem 279, 19531-19539.

DiGirolamo, M., Newby, F. D., Lovejoy, J., 1992. Lactate production in adipose tissue: a regulated function with extra-adipose implications. FASEB J 6, 2405-2412.

Diochot, S., Baron, A., Rash, L. D., Deval, E., Escoubas, P., Scarzello, S., Salinas, M., Lazdunski, M., 2004. A new sea anemone peptide, APETx2, inhibits ASIC3, a major acidsensitive channel in sensory neurons. Embo J 23, 1516-1525.

Diochot, S., Baron, A., Salinas, M., Douguet, D., Scarzello, S., Dabert-Gay, A. S., Debayle, D., Friend, V., Alloui, A., Lazdunski, M., Lingueglia, E., 2012. Black mamba venom peptides target acid-sensing ion channels to abolish pain. Nature 490, 552-555. 
Dorofeeva, N. A., Barygin, O. I., Staruschenko, A., Bolshakov, K. V., Magazanik, L. G., 2008. Mechanisms of non-steroid anti-inflammatory drugs action on ASICs expressed in hippocampal interneurons. J Neurochem 106, 429-441.

Drummond, H. A., Jernigan, N. L., Grifoni, S. C., 2008. Sensing tension: epithelial sodium channel/acid-sensing ion channel proteins in cardiovascular homeostasis. Hypertension 51, 1265-1271.

Du, J., Reznikov, L. R., Price, M. P., Zha, X. M., Lu, Y., Moninger, T. O., Wemmie, J. A., Welsh, M. J., 2014. Protons are a neurotransmitter that regulates synaptic plasticity in the lateral amygdala. Proc Natl Acad Sci U S A 111, 8961-8966.

Duan, B., Wang, Y. Z., Yang, T., Chu, X. P., Yu, Y., Huang, Y., Cao, H., Hansen, J., Simon, R. P., Zhu, M. X., Xiong, Z. G., Xu, T. L., 2011. Extracellular spermine exacerbates ischemic neuronal injury through sensitization of ASIC1a channels to extracellular acidosis. $\mathrm{J}$ Neurosci 31, 2101-2112.

Dube, G. R., Lehto, S. G., Breese, N. M., Baker, S. J., Wang, X., Matulenko, M. A., Honore, P., Stewart, A. O., Moreland, R. B., Brioni, J. D., 2005. Electrophysiological and in vivo characterization of A-317567, a novel blocker of acid sensing ion channels. Pain 117, 88-96.

Dubinnyi, M. A., Osmakov, D. I., Koshelev, S. G., Kozlov, S. A., Andreev, Y. A., Zakaryan, N. A., Dyachenko, I. A., Bondarenko, D. A., Arseniev, A. S., Grishin, E. V., 2012. Lignan from thyme possesses inhibitory effect on ASIC3 channel current. J Biol Chem 287, 32993-33000.

Durrnagel, S., Kuhn, A., Tsiairis, C. D., Williamson, M., Kalbacher, H., Grimmelikhuijzen, C. J., Holstein, T. W., Grunder, S., 2010. Three homologous subunits form a high affinity peptide-gated ion channel in Hydra. J Biol Chem 285, 11958-11965.

Dwyer, J. M., Rizzo, S. J., Neal, S. J., Lin, Q., Jow, F., Arias, R. L., RosenzweigLipson, S., Dunlop, J., Beyer, C. E., 2009. Acid sensing ion channel (ASIC) inhibitors exhibit anxiolytic-like activity in preclinical pharmacological models. Psychopharmacology (Berl) 203, 41-52.

Eisenhut, M., Wallace, H., 2011. Ion channels in inflammation. Pflugers Arch 461, 401-421.

Escoubas, P., Bernard, C., Lambeau, G., Lazdunski, M., Darbon, H., 2003. Recombinant production and solution structure of PcTx1, the specific peptide inhibitor of ASIC1a proton-gated cation channels. Protein Sci 12, 1332-1343. 
Escoubas, P., De Weille, J. R., Lecoq, A., Diochot, S., Waldmann, R., Champigny, G., Moinier, D., Menez, A., Lazdunski, M., 2000. Isolation of a tarantula toxin specific for a class of proton-gated $\mathrm{Na}^{+}$channels. J Biol Chem 275, 25116-25121.

Ettaiche, M., Deval, E., Cougnon, M., Lazdunski, M., Voilley, N., 2006. Silencing acid-sensing ion channel la alters cone-mediated retinal function. J Neurosci 26, 5800-5809.

Ettaiche, M., Deval, E., Pagnotta, S., Lazdunski, M., Lingueglia, E., 2009. Acidsensing ion channel 3 in retinal function and survival. Invest Ophthalmol Vis Sci 50, 24172426.

Ettaiche, M., Guy, N., Hofman, P., Lazdunski, M., Waldmann, R., 2004. Acid-sensing ion channel 2 is important for retinal function and protects against light-induced retinal degeneration. J Neurosci 24, 1005-1012.

Frelin, C., Barbry, P., Vigne, P., Chassande, O., Cragoe, E. J., Jr., Lazdunski, M., 1988. Amiloride and its analogs as tools to inhibit $\mathrm{Na}^{+}$transport via the $\mathrm{Na}^{+}$channel, the $\mathrm{Na}^{+} / \mathrm{H}^{+}$antiport and the $\mathrm{Na}^{+} / \mathrm{Ca}^{2+}$ exchanger. Biochimie 70, 1285-1290.

Frey, E. N., Pavlovicz, R. E., Wegman, C. J., Li, C., Askwith, C. C., 2013. Conformational changes in the lower palm domain of ASIC1a contribute to desensitization and RFamide modulation. PLoS One 8, e71733.

Friese, M. A., Craner, M. J., Etzensperger, R., Vergo, S., Wemmie, J. A., Welsh, M. J., Vincent, A., Fugger, L., 2007. Acid-sensing ion channel-1 contributes to axonal degeneration in autoimmune inflammation of the central nervous system. Nat Med 13, 14831489 .

Fromy, B., Lingueglia, E., Sigaudo-Roussel, D., Saumet, J. L., Lazdunski, M., 2012. Asic3 is a neuronal mechanosensor for pressure-induced vasodilation that protects against pressure ulcers. Nat Med 18, 1205-1207.

Garateix, A., Salceda, E., Menendez, R., Regalado, E. L., Lopez, O., Garcia, T., Morales, R. A., Laguna, A., Thomas, O. P., Soto, E., 2011. Antinociception produced by Thalassia testudinum extract BM-21 is mediated by the inhibition of acid sensing ionic channels by the phenolic compound thalassiolin B. Mol Pain 7, 10.

Garza, A., Lopez-Ramirez, O., Vega, R., Soto, E., 2010. The aminoglycosides modulate the acid-sensing ionic channel currents in dorsal root ganglion neurons from the rat. J Pharmacol Exp Ther 332, 489-499.

Gewehr, C., Oliveira, S. M., Rossato, M. F., Trevisan, G., Dalmolin, G. D., Rigo, F. K., de Castro Junior, C. J., Cordeiro, M. N., Ferreira, J., Gomez, M. V., 2013. Mechanisms 
involved in the nociception triggered by the venom of the armed spider Phoneutria nigriventer. PLoS Negl Trop Dis 7, e2198.

Golubovic, A., Kuhn, A., Williamson, M., Kalbacher, H., Holstein, T. W., Grimmelikhuijzen, C. J., Grunder, S., 2007. A peptide-gated ion channel from the freshwater polyp Hydra. J Biol Chem 282, 35098-35103.

Gonzales, E. B., Kawate, T., Gouaux, E., 2009. Pore architecture and ion sites in acidsensing ion channels and P2X receptors. Nature 460, 599-604.

Gu, L., Yang, Y., Sun, Y., Zheng, X., 2010. Puerarin inhibits acid-sensing ion channels and protects against neuron death induced by acidosis. Planta Med 76, 583-588.

Guo, W., Chen, X., He, J. J., Wei, Y. J., Zang, Z. L., Liu, S. Y., Yang, H., Zhang, C. Q., 2014. Down-regulated expression of acid-sensing ion channel 1a in cortical lesions of patients with focal cortical dysplasia. J Mol Neurosci 53, 176-182.

Hayes, S. G., Kindig, A. E., Kaufman, M. P., 2007. Blockade of acid sensing ion channels attenuates the exercise pressor reflex in cats. J Physiol 581, 1271-1282.

Holland, P. R., Akerman, S., Andreou, A. P., Karsan, N., Wemmie, J. A., Goadsby, P. J., 2012. Acid-sensing ion channel 1: a novel therapeutic target for migraine with aura. Ann Neurol 72, 559-563.

Hu, R., Duan, B., Wang, D., Yu, Y., Li, W., Luo, H., Lu, P., Lin, J., Zhu, G., Wan, Q., Feng, H., 2011. Role of acid-sensing ion channel 1a in the secondary damage of traumatic spinal cord injury. Ann Surg 254, 353-362.

Hu, W., Chen, F. H., Yuan, F. L., Zhang, T. Y., Wu, F. R., Rong, C., Jiang, S., Tang, J., Zhang, C. C., Lin, M. Y., 2012. Blockade of acid-sensing ion channels protects articular chondrocytes from acid-induced apoptotic injury. Inflamm Res 61, 327-335.

Huang, S. J., Yang, W. S., Lin, Y. W., Wang, H. C., Chen, C. C., 2008. Increase of insulin sensitivity and reversal of age-dependent glucose intolerance with inhibition of ASIC3. Biochem Biophys Res Commun 371, 729-734.

Huda, R., Pollema-Mays, S. L., Chang, Z., Alheid, G. F., McCrimmon, D. R., Martina, M., 2012. Acid-sensing ion channels contribute to chemosensitivity of breathing-related neurons of the nucleus of the solitary tract. J Physiol 590, 4761-4775.

Ikeuchi, M., Kolker, S. J., Sluka, K. A., 2009. Acid-sensing ion channel 3 expression in mouse knee joint afferents and effects of carrageenan-induced arthritis. J Pain 10, 336-342.

Immke, D. C., McCleskey, E. W., 2001a. ASIC3: a lactic acid sensor for cardiac pain. ScientificWorldJournal 1, 510-512. 
Immke, D. C., McCleskey, E. W., 2001b. Lactate enhances the acid-sensing $\mathrm{Na}^{+}$ channel on ischemia-sensing neurons. Nat Neurosci 4, 869-870.

Immke, D. C., McCleskey, E. W., 2003. Protons open acid-sensing ion channels by catalyzing relief of $\mathrm{Ca}^{2+}$ blockade. Neuron $37,75-84$.

Izumi, M., Ikeuchi, M., Ji, Q., Tani, T., 2012. Local ASIC3 modulates pain and disease progression in a rat model of osteoarthritis. J Biomed Sci 19, 77.

Jahr, H., van Driel, M., van Osch, G. J., Weinans, H., van Leeuwen, J. P., 2005. Identification of acid-sensing ion channels in bone. Biochem Biophys Res Commun 337, 349354.

Jasti, J., Furukawa, H., Gonzales, E. B., Gouaux, E., 2007. Structure of acid-sensing ion channel 1 at 1.9 A resolution and low pH. Nature 449, 316-323.

Jensen, J. E., Durek, T., Alewood, P. F., Adams, D. J., King, G. F., Rash, L. D., 2009. Chemical synthesis and folding of APETx2, a potent and selective inhibitor of acid sensing ion channel 3. Toxicon 54, 56-61.

Jeong, S., Lee, S. H., Kim, Y. O., Yoon, M. H., 2013. Antinociceptive effects of amiloride and benzamil in neuropathic pain model rats. J Korean Med Sci 28, 1238-1243.

Jernigan, N. L., Herbert, L. M., Walker, B. R., Resta, T. C., 2012. Chronic hypoxia upregulates pulmonary arterial ASIC1: a novel mechanism of enhanced store-operated $\mathrm{Ca}^{2+}$ entry and receptor-dependent vasoconstriction. Am J Physiol Cell Physiol 302, C931-940.

Jernigan, N. L., Paffett, M. L., Walker, B. R., Resta, T. C., 2009. ASIC1 contributes to pulmonary vascular smooth muscle store-operated $\mathrm{Ca}^{2+}$ entry. Am J Physiol Lung Cell Mol Physiol 297, L271-285.

Jetti, S. K., Swain, S. M., Majumder, S., Chatterjee, S., Poornima, V., Bera, A. K., 2010. Evaluation of the role of nitric oxide in acid sensing ion channel mediated cell death. Nitric Oxide 22, 213-219.

Jiang, Q., Inoue, K., Wu, X., Papasian, C. J., Wang, J. Q., Xiong, Z. G., Chu, X. P., 2011. Cysteine 149 in the extracellular finger domain of acid-sensing ion channel $1 \mathrm{~b}$ subunit is critical for zinc-mediated inhibition. Neuroscience 193, 89-99.

Jiang, Q., Papasian, C. J., Wang, J. Q., Xiong, Z. G., Chu, X. P., 2010. Inhibitory regulation of acid-sensing ion channel 3 by zinc. Neuroscience 169, 574-583.

Jones, N. G., Slater, R., Cadiou, H., McNaughton, P., McMahon, S. B., 2004. Acidinduced pain and its modulation in humans. J Neurosci 24, 10974-10979. 
Karczewski, J., Spencer, R. H., Garsky, V. M., Liang, A., Leitl, M. D., Cato, M. J., Cook, S. P., Kane, S., Urban, M. O., 2010. Reversal of acid-induced and inflammatory pain by the selective ASIC3 inhibitor, APETx2. Br J Pharmacol 161, 950-960.

Kellenberger, S., Gautschi, I., Schild, L., 2003. Mutations in the epithelial $\mathrm{Na}^{+}$channel $\mathrm{ENaC}$ outer pore disrupt amiloride block by increasing its dissociation rate. Mol Pharmacol 64, 848-856.

Kleyman, T. R., Cragoe, E. J., Jr., 1988. Amiloride and its analogs as tools in the study of ion transport. J Membr Biol 105, 1-21.

Kolker, S. J., Walder, R. Y., Usachev, Y., Hillman, J., Boyle, D. L., Firestein, G. S., Sluka, K. A., 2010. Acid-sensing ion channel 3 expressed in type B synoviocytes and chondrocytes modulates hyaluronan expression and release. Ann Rheum Dis 69, 903-909.

Kreple, C. J., Lu, Y., Taugher, R. J., Schwager-Gutman, A. L., Du, J., Stump, M., Wang, Y., Ghobbeh, A., Fan, R., Cosme, C. V., Sowers, L. P., Welsh, M. J., Radley, J. J., LaLumiere, R. T., Wemmie, J. A., 2014. Acid-sensing ion channels contribute to synaptic transmission and inhibit cocaine-evoked plasticity. Nat Neurosci 17, 1083-1091.

Kuduk, S. D., Chang, R. K., Di Marco, C. N., Dipardo, R. M., Cook, S. P., Cato, M. J., Jovanovska, A., Urban, M. O., Leitl, M., Spencer, R. H., Kane, S. A., Hartman, G. D., Bilodeau, M. T., 2011. Identification of non-amidine inhibitors of acid-sensing ion channel-3 (ASIC3). Bioorg Med Chem Lett 21, 4255-4258.

Kuduk, S. D., Di Marco, C. N., Bodmer-Narkevitch, V., Cook, S. P., Cato, M. J., Jovanovska, A., Urban, M. O., Leitl, M., Sain, N., Liang, A., Spencer, R. H., Kane, S. A., Hartman, G. D., Bilodeau, M. T., 2010. Synthesis, structure-activity relationship, and pharmacological profile of analogs of the ASIC-3 inhibitor A-317567. ACS Chem Neurosci 1, 19-24.

Kuduk, S. D., Di Marco, C. N., Chang, R. K., Dipardo, R. M., Cook, S. P., Cato, M. J., Jovanovska, A., Urban, M. O., Leitl, M., Spencer, R. H., Kane, S. A., Bilodeau, M. T., Hartman, G. D., Bock, M. G., 2009. Amiloride derived inhibitors of acid-sensing ion channel3 (ASIC3). Bioorg Med Chem Lett 19, 2514-2518.

Lei, Z., Li, X., Wang, G., Fei, J., Meng, T., Zhang, X., Yu, J., Li, J., 2014. Inhibition of acid-sensing ion channel currents by propofol in rat dorsal root ganglion neurons. Clin Exp Pharmacol Physiol 41, 295-300.

Leng, T., Lin, J., Cottrell, J. E., Xiong, Z. G., 2013. Subunit and frequency-dependent inhibition of Acid Sensing Ion Channels by local anesthetic tetracaine. Mol Pain 9, 27. 
Li, W. G., Xu, T. L., 2011. ASIC3 Channels in Multimodal Sensory Perception. ACS Chem Neurosci 2, 26-37.

Li, W. G., Yu, Y., Huang, C., Cao, H., Xu, T. L., 2011. Nonproton ligand sensing domain is required for paradoxical stimulation of acid-sensing ion channel 3 (ASIC3) channels by amiloride. J Biol Chem 286, 42635-42646.

Li, W. G., Yu, Y., Zhang, Z. D., Cao, H., Xu, T. L., 2010. ASIC3 channels integrate agmatine and multiple inflammatory signals through the nonproton ligand sensing domain. Mol Pain 6, 88.

Li, X., Fei, J., Lei, Z., Liu, K., Wu, J., Meng, T., Yu, J., Li, J., 2014a. Chloroquine impairs visual transduction via modulation of acid sensing ion channel 1a. Toxicol Lett 228, 200-206.

Li, X., Wu, F. R., Xu, R. S., Hu, W., Jiang, D. L., Ji, C., Chen, F. H., Yuan, F. L., 2014b. Acid-sensing ion channel 1a-mediated calcium influx regulates apoptosis of endplate chondrocytes in intervertebral discs. Expert Opin Ther Targets 18, 1-14.

Li, X., Xu, R. S., Jiang, D. L., He, X. L., Jin, C., Lu, W. G., Su, Q., Yuan, F. L., 2013. Acid-sensing ion channel 1a is involved in acid-induced osteoclastogenesis by regulating activation of the transcription factor NFATc1. FEBS Lett 587, 3236-3242.

Lin, J., Chu, X., Maysami, S., Li, M., Si, H., Cottrell, J. E., Simon, R. P., Xiong, Z., 2011. Inhibition of acid sensing ion channel currents by lidocaine in cultured mouse cortical neurons. Anesth Analg 112, 977-981.

Lingueglia, E., Champigny, G., Lazdunski, M., Barbry, P., 1995. Cloning of the amiloride-sensitive FMRFamide peptide-gated sodium channel. Nature 378, 730-733.

Lingueglia, E., Deval, E., Lazdunski, M., 2006. FMRFamide-gated sodium channel and ASIC channels: a new class of ionotropic receptors for FMRFamide and related peptides. Peptides 27, 1138-1152.

Lu, Y., Ma, X., Sabharwal, R., Snitsarev, V., Morgan, D., Rahmouni, K., Drummond, H. A., Whiteis, C. A., Costa, V., Price, M., Benson, C., Welsh, M. J., Chapleau, M. W., Abboud, F. M., 2009. The ion channel ASIC2 is required for baroreceptor and autonomic control of the circulation. Neuron 64, 885-897.

Luszczki, J. J., Sawicka, K. M., Kozinska, J., Dudra-Jastrzebska, M., Czuczwar, S. J., 2009. Amiloride enhances the anticonvulsant action of various antiepileptic drugs in the mouse maximal electroshock seizure model. J Neural Transm 116, 57-66. 
Lv, R. J., He, J. S., Fu, Y. H., Zhang, Y. Q., Shao, X. Q., Wu, L. W., Lu, Q., Jin, L. R., Liu, H., 2011. ASIC1a polymorphism is associated with temporal lobe epilepsy. Epilepsy Res 96, 74-80.

Mango, D., Barbato, G., Piccirilli, S., Panico, M. B., Feligioni, M., Schepisi, C., Graziani, M., Porrini, V., Benarese, M., Lanzillotta, A., Pizzi, M., Pieraccini, S., Sironi, M., Blandini, F., Nicoletti, F., Mercuri, N. B., Imbimbo, B. P., Nistico, R., 2014. Electrophysiological and metabolic effects of CHF5074 in the hippocampus: protection against in vitro ischemia. Pharmacol Res 81, 83-90.

Matricon, J., Gelot, A., Etienne, M., Lazdunski, M., Muller, E., Ardid, D., 2011. Spinal cord plasticity and acid-sensing ion channels involvement in a rodent model of irritable bowel syndrome. Eur J Pain 15, 335-343.

Mazzuca, M., Heurteaux, C., Alloui, A., Diochot, S., Baron, A., Voilley, N., Blondeau, N., Escoubas, P., Gelot, A., Cupo, A., Zimmer, A., Zimmer, A. M., Eschalier, A., Lazdunski, M., 2007. A tarantula peptide against pain via ASIC1a channels and opioid mechanisms. Nat Neurosci 10, 943-945.

McCord, J. L., Tsuchimochi, H., Kaufman, M. P., 2009. Acid-sensing ion channels contribute to the metaboreceptor component of the exercise pressor reflex. Am J Physiol Heart Circ Physiol 297, H443-449.

McMahon, S. B., Jones, N. G., 2004. Plasticity of pain signaling: role of neurotrophic factors exemplified by acid-induced pain. J Neurobiol 61, 72-87.

Mercado, F., Almanza, A., Simon-Arceo, K., Lopez, O., Vega, R., Coffeen, U., Contreras, B., Soto, E., Pellicer, F., 2014. Inhibition of Peripheral Nociceptors by Aminoglycosides Produces Analgesia in Inflammatory Pain Models in the Rat. Inflammation In press.

Mishra, V., Verma, R., Raghubir, R., 2010. Neuroprotective effect of flurbiprofen in focal cerebral ischemia: the possible role of ASIC1a. Neuropharmacology 59, 582-588.

Miyake, T., Nishiwaki, A., Yasukawa, T., Ugawa, S., Shimada, S., Ogura, Y., 2013. Possible implications of acid-sensing ion channels in ischemia-induced retinal injury in rats. Jpn J Ophthalmol 57, 120-125.

Mogil, J. S., Breese, N. M., Witty, M. F., Ritchie, J., Rainville, M. L., Ase, A., Abbadi, N., Stucky, C. L., Seguela, P., 2005. Transgenic expression of a dominant-negative ASIC3 subunit leads to increased sensitivity to mechanical and inflammatory stimuli. J Neurosci 25, 9893-9901. 
Molliver, D. C., Immke, D. C., Fierro, L., Pare, M., Rice, F. L., McCleskey, E. W., 2005. ASIC3, an acid-sensing ion channel, is expressed in metaboreceptive sensory neurons. Mol Pain 1, 35.

N'Gouemo, P., 2008. Amiloride delays the onset of pilocarpine-induced seizures in rats. Brain Res 1222, 230-232.

Noël, J., Salinas, M., Baron, A., Diochot, S., Deval, E., Lingueglia, E., 2010. Current perspectives on acid-sensing ion channels: new advances and therapeutic implications. Expert Review of Clinical Pharmacology 3, 331-346.

Osmakov, D. I., Kozlov, S. A., Andreev, Y. A., Koshelev, S. G., Sanamyan, N. P., Sanamyan, K. E., Dyachenko, I. A., Bondarenko, D. A., Murashev, A. N., Mineev, K. S., Arseniev, A. S., Grishin, E. V., 2013. Sea anemone peptide with uncommon beta-hairpin structure inhibits acid-sensing ion channel 3 (ASIC3) and reveals analgesic activity. J Biol Chem 288, 23116-23127.

Page, A. J., Brierley, S. M., Martin, C. M., Martinez-Salgado, C., Wemmie, J. A., Brennan, T. J., Symonds, E., Omari, T., Lewin, G. R., Welsh, M. J., Blackshaw, L. A., 2004. The ion channel ASIC1 contributes to visceral but not cutaneous mechanoreceptor function. Gastroenterology 127, 1739-1747.

Pan, C. X., Wu, F. R., Wang, X. Y., Tang, J., Gao, W. F., Ge, J. F., Chen, F. H., 2014. Inhibition of ASICs reduces rat hepatic stellate cells activity and liver fibrosis: An in vitro and in vivo study. Cell Biol Int In press.

Paukert, M., Babini, E., Pusch, M., Grunder, S., 2004. Identification of the $\mathrm{Ca}^{2+}$ blocking site of acid-sensing ion channel (ASIC) 1: implications for channel gating. J Gen Physiol 124, 383-394.

Paukert, M., Chen, X., Polleichtner, G., Schindelin, H., Grunder, S., 2008. Candidate amino acids involved in $\mathrm{H}^{+}$gating of acid-sensing ion channel 1a. J Biol Chem 283, 572-581.

Peigneur, S., Beress, L., Moller, C., Mari, F., Forssmann, W. G., Tytgat, J., 2012. A natural point mutation changes both target selectivity and mechanism of action of sea anemone toxins. FASEB J 26, 5141-5151.

Pidoplichko, V. I., Dani, J. A., 2006. Acid-sensitive ionic channels in midbrain dopamine neurons are sensitive to ammonium, which may contribute to hyperammonemia damage. Proc Natl Acad Sci U S A 103, 11376-11380.

Pignataro, G., Simon, R. P., Xiong, Z. G., 2007. Prolonged activation of ASIC1a and the time window for neuroprotection in cerebral ischaemia. Brain 130, 151-158. 
Poirot, O., Berta, T., Decosterd, I., Kellenberger, S., 2006. Distinct ASIC currents are expressed in rat putative nociceptors and are modulated by nerve injury. J Physiol 576, 215 234.

Price, M. P., McIlwrath, S. L., Xie, J., Cheng, C., Qiao, J., Tarr, D. E., Sluka, K. A., Brennan, T. J., Lewin, G. R., Welsh, M. J., 2001. The DRASIC cation channel contributes to the detection of cutaneous touch and acid stimuli in mice. Neuron 32, 1071-1083.

Qiu, F., Liu, T. T., Qu, Z. W., Qiu, C. Y., Yang, Z., Hu, W. P., 2014. Gastrodin inhibits the activity of acid-sensing ion channels in rat primary sensory neurons. Eur $\mathrm{J}$ Pharmacol 731, 50-57.

Qiu, F., Qiu, C. Y., Liu, Y. Q., Wu, D., Li, J. D., Hu, W. P., 2012. Potentiation of acidsensing ion channel activity by the activation of 5-HT(2) receptors in rat dorsal root ganglion neurons. Neuropharmacology 63, 494-500.

Qu, Z. W., Liu, T. T., Qiu, C. Y., Li, J. D., Hu, W. P., 2014. Inhibition of acid-sensing ion channels by chlorogenic acid in rat dorsal root ganglion neurons. Neurosci Lett 567, 35 39.

Quansah, H., N'Gouemo, P., 2014. Amiloride and SN-6 Suppress Audiogenic Seizure Susceptibility in Genetically Epilepsy-Prone Rats. CNS Neurosci Ther in press.

Rahman, T., Smith, E. S., 2014. In silico assessment of interaction of sea anemone toxin APETx2 and acid sensing ion channel 3. Biochem Biophys Res Commun 450, 384-389.

Rocha-Gonzalez, H. I., Herrejon-Abreu, E. B., Lopez-Santillan, F. J., Garcia-Lopez, B. E., Murbartian, J., Granados-Soto, V., 2009. Acid increases inflammatory pain in rats: effect of local peripheral ASICs inhibitors. Eur J Pharmacol 603, 56-61.

Rodriguez, A. A., Salceda, E., Garateix, A. G., Zaharenko, A. J., Peigneur, S., Lopez, O., Pons, T., Richardson, M., Diaz, M., Hernandez, Y., Standker, L., Tytgat, J., Soto, E., 2014. A novel sea anemone peptide that inhibits acid-sensing ion channels. Peptides 53, 3-12.

Romey, G., Abita, J. P., Schweitz, H., Wunderer, G., Lazdunski, 1976. Sea anemone toxin:a tool to study molecular mechanisms of nerve conduction and excitation-secretion coupling. Proc Natl Acad Sci U S A 73, 4055-4059.

Rooj, A. K., McNicholas, C. M., Bartoszewski, R., Bebok, Z., Benos, D. J., Fuller, C. M., 2012. Glioma-specific cation conductance regulates migration and cell cycle progression. J Biol Chem 287, 4053-4065.

Saez, N. J., Mobli, M., Bieri, M., Chassagnon, I. R., Malde, A. K., Gamsjaeger, R., Mark, A. E., Gooley, P. R., Rash, L. D., King, G. F., 2011. A dynamic pharmacophore drives 
the interaction between Psalmotoxin-1 and the putative drug target acid-sensing ion channel 1a. Mol Pharmacol 80, 796-808.

Salinas, M., Besson, T., Delettre, Q., Diochot, S., Boulakirba, S., Douguet, D., Lingueglia, E., 2014. Binding site and inhibitory mechanism of the mambalgin-2 painrelieving peptide on acid-sensing ion channel 1a. J Biol Chem 289, 13363-13373.

Schild, L., Schneeberger, E., Gautschi, I., Firsov, D., 1997. Identification of amino acid residues in the alpha, beta, and gamma subunits of the epithelial sodium channel (ENaC) involved in amiloride block and ion permeation. J Gen Physiol 109, 15-26.

Schroeder, C. I., Rash, L. D., Vila-Farres, X., Rosengren, K. J., Mobli, M., King, G. F., Alewood, P. F., Craik, D. J., Durek, T., 2014. Chemical synthesis, 3D structure, and ASIC binding site of the toxin mambalgin-2. Angew Chem Int Ed Eng1 53, 1017-1020.

Sherwood, T. W., Askwith, C. C., 2008. Endogenous arginine-phenylalanine-amiderelated peptides alter steady-state desensitization of ASIC1a. J Biol Chem 283, 1818-1830.

Sherwood, T. W., Askwith, C. C., 2009. Dynorphin opioid peptides enhance acidsensing ion channel 1a activity and acidosis-induced neuronal death. J Neurosci 29, 1437114380.

Sherwood, T. W., Lee, K. G., Gormley, M. G., Askwith, C. C., 2011. Heteromeric Acid-Sensing Ion Channels (ASICs) Composed of ASIC2b and ASIC1a Display Novel Channel Properties and Contribute to Acidosis-Induced Neuronal Death. J Neurosci 31, 9723 9734.

Sluka, K. A., Price, M. P., Breese, N. M., Stucky, C. L., Wemmie, J. A., Welsh, M. J., 2003. Chronic hyperalgesia induced by repeated acid injections in muscle is abolished by the loss of ASIC3, but not ASIC1. Pain 106, 229-239.

Sluka, K. A., Radhakrishnan, R., Benson, C. J., Eshcol, J. O., Price, M. P., Babinski, K., Audette, K. M., Yeomans, D. C., Wilson, S. P., 2007. ASIC3 in muscle mediates mechanical, but not heat, hyperalgesia associated with muscle inflammation. Pain 129, 102112.

Smith, E. S., Cadiou, H., McNaughton, P. A., 2007. Arachidonic acid potentiates acidsensing ion channels in rat sensory neurons by a direct action. Neuroscience 145, 686-698.

Smoller, J. W., Gallagher, P. J., Duncan, L. E., McGrath, L. M., Haddad, S. A., Holmes, A. J., Wolf, A. B., Hilker, S., Block, S. R., Weill, S., Young, S., Choi, E. Y., Rosenbaum, J. F., Biederman, J., Faraone, S. V., Roffman, J. L., Manfro, G. G., Blaya, C., Hirshfeld-Becker, D. R., Stein, M. B., Van Ameringen, M., Tolin, D. F., Otto, M. W., 
Pollack, M. H., Simon, N. M., Buckner, R. L., Ongur, D., Cohen, B. M., 2014. The Human Ortholog of Acid-Sensing Ion Channel Gene ASIC1a Is Associated with Panic Disorder and Amygdala Structure and Function. Biol Psychiatry in press.

Song, N., Zhang, G., Geng, W., Liu, Z., Jin, W., Li, L., Cao, Y., Zhu, D., Yu, J., Shen, L., 2012. Acid sensing ion channel 1 in lateral hypothalamus contributes to breathing control. PLoS One 7, e39982.

Staruschenko, A., Dorofeeva, N. A., Bolshakov, K. V., Stockand, J. D., 2007. Subunitdependent cadmium and nickel inhibition of acid-sensing ion channels. Dev Neurobiol 67, 97 107.

Steen, K. H., Steen, A. E., Reeh, P. W., 1995. A dominant role of acid pH in inflammatory excitation and sensitization of nociceptors in rat skin, in vitro. J Neurosci 15 , 3982-3989.

Sun, X., Cao, Y. B., Hu, L. F., Yang, Y. P., Li, J., Wang, F., Liu, C. F., 2011. ASICs mediate the modulatory effect by paeoniflorin on alpha-synuclein autophagic degradation. Brain Res 1396, 77-87.

Tai, K. K., Truong, D. D., 2013. Amiloride but not memantine reduces neurodegeneration, seizures and myoclonic jerks in rats with cardiac arrest-induced global cerebral hypoxia and reperfusion. PLoS One 8, e60309.

Tan, J., Ye, X., Xu, Y., Wang, H., Sheng, M., Wang, F., 2011. Acid-sensing ion channel 1a is involved in retinal ganglion cell death induced by hypoxia. Mol Vis 17, 33003308 .

Tsuchimochi, H., Yamauchi, K., McCord, J. L., Kaufman, M. P., 2011. Blockade of acid sensing ion channels attenuates the augmented exercise pressor reflex in rats with chronic femoral artery occlusion. J Physiol 589, 6173-6189.

Ugawa, S., Ishida, Y., Ueda, T., Inoue, K., Nagao, M., Shimada, S., 2007. Nafamostat mesilate reversibly blocks acid-sensing ion channel currents. Biochem Biophys Res Commun 363, 203-208.

Ugawa, S., Ueda, T., Ishida, Y., Nishigaki, M., Shibata, Y., Shimada, S., 2002. Amiloride-blockable acid-sensing ion channels are leading acid sensors expressed in human nociceptors. J Clin Invest 110, 1185-1190.

Vergo, S., Craner, M. J., Etzensperger, R., Attfield, K., Friese, M. A., Newcombe, J., Esiri, M., Fugger, L., 2011. Acid-sensing ion channel 1 is involved in both axonal injury and demyelination in multiple sclerosis and its animal model. Brain 134, 571-584. 
Voilley, N., 2004. Acid-sensing ion channels (ASICs): new targets for the analgesic effects of non-steroid anti-inflammatory drugs (NSAIDs). Curr Drug Targets Inflamm Allergy $3,71-79$.

Voilley, N., de Weille, J., Mamet, J., Lazdunski, M., 2001. Nonsteroid antiinflammatory drugs inhibit both the activity and the inflammation-induced expression of acidsensing ion channels in nociceptors. J Neurosci 21, 8026-8033.

Walder, R. Y., Gautam, M., Wilson, S. P., Benson, C. J., Sluka, K. A., 2011. Selective targeting of ASIC3 using artificial miRNAs inhibits primary and secondary hyperalgesia after muscle inflammation. Pain 152, 2348-2356.

Walder, R. Y., Rasmussen, L. A., Rainier, J. D., Light, A. R., Wemmie, J. A., Sluka, K. A., 2010. ASIC1 and ASIC3 play different roles in the development of Hyperalgesia after inflammatory muscle injury. J Pain 11, 210-218.

Waldmann, R., Bassilana, F., de Weille, J., Champigny, G., Heurteaux, C., Lazdunski, M., 1997a. Molecular cloning of a non-inactivating proton-gated $\mathrm{Na}^{+}$channel specific for sensory neurons. J Biol Chem 272, 20975-20978.

Waldmann, R., Champigny, G., Bassilana, F., Heurteaux, C., Lazdunski, M., 1997b. A proton-gated cation channel involved in acid-sensing. Nature 386, 173-177.

Waldmann, R., Champigny, G., Voilley, N., Lauritzen, I., Lazdunski, M., 1996. The mammalian degenerin MDEG, an amiloride-sensitive cation channel activated by mutations causing neurodegeneration in Caenorhabditis elegans. J Biol Chem 271, 10433-10436.

Wang, W., Duan, B., Xu, H., Xu, L., Xu, T. L., 2006. Calcium-permeable acid-sensing ion channel is a molecular target of the neurotoxic metal ion lead. J Biol Chem 281, 2497 2505 .

Wang, W., Ye, S. D., Zhou, K. Q., Wu, L. M., Huang, Y. N., 2012. High doses of salicylate and aspirin are inhibitory on acid-sensing ion channels and protective against acidosis-induced neuronal injury in the rat cortical neuron. J Neurosci Res 90, 267-277.

Wang, W., Yu, Y., Xu, T. L., 2007. Modulation of acid-sensing ion channels by $\mathrm{Cu}^{2+}$ in cultured hypothalamic neurons of the rat. Neuroscience 145, 631-641.

Wang, X., Li, W. G., Yu, Y., Xiao, X., Cheng, J., Zeng, W. Z., Peng, Z., Xi Zhu, M., $\mathrm{Xu}, \mathrm{T}$. L., 2013. Serotonin facilitates peripheral pain sensitivity in a manner that depends on the nonproton ligand sensing domain of ASIC3 channel. J Neurosci 33, 4265-4279. 
Wemmie, J. A., Askwith, C. C., Lamani, E., Cassell, M. D., Freeman, J. H., Jr., Welsh, M. J., 2003. Acid-sensing ion channel 1 is localized in brain regions with high synaptic density and contributes to fear conditioning. J Neurosci 23, 5496-5502.

Wemmie, J. A., Chen, J., Askwith, C. C., Hruska-Hageman, A. M., Price, M. P., Nolan, B. C., Yoder, P. G., Lamani, E., Hoshi, T., Freeman, J. H., Jr., Welsh, M. J., 2002. The acid-activated ion channel ASIC contributes to synaptic plasticity, learning, and memory. Neuron 34, 463-477.

Wemmie, J. A., Coryell, M. W., Askwith, C. C., Lamani, E., Leonard, A. S., Sigmund, C. D., Welsh, M. J., 2004. Overexpression of acid-sensing ion channel 1a in transgenic mice increases acquired fear-related behavior. Proc Natl Acad Sci U S A 101, 3621-3626.

Wong, H. K., Bauer, P. O., Kurosawa, M., Goswami, A., Washizu, C., Machida, Y., Tosaki, A., Yamada, M., Knopfel, T., Nakamura, T., Nukina, N., 2008. Blocking acid-sensing ion channel 1 alleviates Huntington's disease pathology via an ubiquitin-proteasome systemdependent mechanism. Hum Mol Genet 17, 3223-3235.

Wu, F. R., Pan, C. X., Rong, C., Xia, Q., Yuan, F. L., Tang, J., Wang, X. Y., Wang, N., Ni, W. L., Chen, F. H., 2014. Inhibition of acid-sensing ion channel 1a in hepatic stellate cells attenuates PDGF-induced activation of HSCs through MAPK pathway. Mol Cell Biochem in press.

Xiao, X., Zhu, M. X., Xu, T. L., 2013. 2-Guanidine-4-methylquinazoline acts as a novel competitive antagonist of A type gamma-aminobutyric acid receptors. Neuropharmacology 75, 126-137.

Xiong, Z. G., Pignataro, G., Li, M., Chang, S. Y., Simon, R. P., 2008. Acid-sensing ion channels (ASICs) as pharmacological targets for neurodegenerative diseases. Curr Opin Pharmacol 8, 25-32.

Xiong, Z. G., Zhu, X. M., Chu, X. P., Minami, M., Hey, J., Wei, W. L., MacDonald, J. F., Wemmie, J. A., Price, M. P., Welsh, M. J., Simon, R. P., 2004. Neuroprotection in ischemia: blocking calcium-permeable acid-sensing ion channels. Cell 118, 687-698.

Yagi, J., Wenk, H. N., Naves, L. A., McCleskey, E. W., 2006. Sustained currents through ASIC3 ion channels at the modest $\mathrm{pH}$ changes that occur during myocardial ischemia. Circ Res 99, 501-509.

Yan, J., Edelmayer, R. M., Wei, X., De Felice, M., Porreca, F., Dussor, G., 2011. Dural afferents express acid-sensing ion channels: a role for decreased meningeal $\mathrm{pH}$ in migraine headache. Pain 152, 106-113. 
Yan, J., Wei, X., Bischoff, C., Edelmayer, R. M., Dussor, G., 2013. pH-evoked dural afferent signaling is mediated by ASIC3 and is sensitized by mast cell mediators. Headache $53,1250-1261$.

Yang, Z. J., Ni, X., Carter, E. L., Kibler, K., Martin, L. J., Koehler, R. C., 2011. Neuroprotective effect of acid-sensing ion channel inhibitor psalmotoxin-1 after hypoxiaischemia in newborn piglet striatum. Neurobiol Dis 43, 446-454.

Young, G. T., Gutteridge, A., Fox, H. D., Wilbrey, A. L., Cao, L., Cho, L. T., Brown, A. R., Benn, C. L., Kammonen, L. R., Friedman, J. H., Bictash, M., Whiting, P., Bilsland, J. G., Stevens, E. B., 2014. Characterizing Human Stem Cell-derived Sensory Neurons at the Single-cell Level Reveals Their Ion Channel Expression and Utility in Pain Research. Mol Ther in press.

Yu, Y., Chen, Z., Li, W. G., Cao, H., Feng, E. G., Yu, F., Liu, H., Jiang, H., Xu, T. L., 2010. A nonproton ligand sensor in the acid-sensing ion channel. Neuron 68, 61-72.

Yu, Y., Li, W. G., Chen, Z., Cao, H., Yang, H., Jiang, H., Xu, T. L., 2011. Atomic level characterization of the nonproton ligand-sensing domain of ASIC3 channels. J Biol Chem 286, 24996-25006.

Yuan, F. L., Chen, F. H., Lu, W. G., Li, X., Li, J. P., Li, C. W., Xu, R. S., Wu, F. R., $\mathrm{Hu}$, W., Zhang, T. Y., 2010a. Inhibition of acid-sensing ion channels in articular chondrocytes by amiloride attenuates articular cartilage destruction in rats with adjuvant arthritis. Inflamm Res 59, 939-947.

Yuan, F. L., Chen, F. H., Lu, W. G., Li, X., Wu, F. R., Li, J. P., Li, C. W., Wang, Y., Zhang, T. Y., Hu, W., 2010b. Acid-sensing ion channel 1a mediates acid-induced increases in intracellular calcium in rat articular chondrocytes. Mol Cell Biochem 340, 153-159.

Zhou, Y. X., Zhang, H., Peng, C., 2013. Puerarin: A Review of Pharmacological Effects. Phytother Res 28, 961-975.

Ziemann, A. E., Schnizler, M. K., Albert, G. W., Severson, M. A., Howard, M. A., 3rd, Welsh, M. J., Wemmie, J. A., 2008. Seizure termination by acidosis depends on ASIC1a. Nat Neurosci 11, 816-822. 
Table 1

\begin{tabular}{|c|c|c|c|}
\hline ASIC-targeting drugs & $\begin{array}{l}\text { Pharmacological/ } \\
\text { Therapeutic class }\end{array}$ & $\begin{array}{l}\text { Effective } \\
\text { concentration range }\end{array}$ & $\begin{array}{l}\text { ASIC channels } \\
\text { involved }\end{array}$ \\
\hline Amiloride & Diuretic & $\begin{array}{l}\mathrm{IC}_{50} \sim 5-100 \mu \mathrm{M} \\
\mathrm{EC}_{50} \sim 560 \mu \mathrm{M}\end{array}$ & $\begin{array}{l}\text { All } \\
\text { ASIC3, ASIC3+1b }\end{array}$ \\
\hline GMQ & Amiloride-derived & $\mathrm{EC}_{50} \sim 1 \mathrm{mM}$ & ASIC3 \\
\hline Flurbiprofen, ibuprofen & NSAID & $\mathrm{IC}_{50} \sim 350 \mu \mathrm{M}$ & ASIC1a \\
\hline $\begin{array}{l}\text { Salicylic acid, aspirin, } \\
\text { diclofenac }\end{array}$ & NSAID & $\mathrm{IC}_{50} \sim 90-260 \mu \mathrm{M}$ & ASIC3, ASIC2a \\
\hline CHF5074 & NSAID-derived & $\mathrm{IC}_{50} \sim 50 \mathrm{nM}$ & $\begin{array}{l}\text { Native channels in } \\
\text { hippocampal neurons }\end{array}$ \\
\hline Tetraethylammonium (TEA) & $\begin{array}{l}\text { Cation, Kv channel } \\
\text { inhibitor }\end{array}$ & $\mathrm{mM}$ range & $\mathrm{ASIC} 1 \mathrm{a}+2 \mathrm{a} / 2 \mathrm{~b}$ \\
\hline 4-aminopyridine (4AP) & Kv channel inhibitor & $\mathrm{IC}_{50} \sim 760 \mu \mathrm{M}$ & All except ASIC3 \\
\hline Tetracaine & Local anesthetic & $\mathrm{IC}_{50} \sim 10 \mathrm{mM}$ & ASIC3, ASIC1b \\
\hline Lidocaine & Local anesthetic & $\mathrm{IC}_{50} \sim 12 \mathrm{mM}$ & ASIC1a \\
\hline Propofol & Anesthetic & $30-300 \mu \mathrm{M}$ range & ASIC1a, ASIC3 \\
\hline A-317567 & Amidine & $\mathrm{IC}_{50} \sim 2-30 \mu \mathrm{M}$ & ASIC3 \\
\hline Benzothiophene methyl amine & & $\mathrm{IC}_{50} \sim 0.22 \mu \mathrm{M}$ & ASIC3, ASIC1a \\
\hline Streptomycin, neomycin & $\begin{array}{l}\text { Antibiotics, } \\
\text { aminoglycosides }\end{array}$ & $\mathrm{IC}_{50} \sim 32-44 \mu \mathrm{M}$ & $\begin{array}{l}\text { Native channels in } \\
\text { sensory neurons }\end{array}$ \\
\hline Nafamostat mesilate & Anticoagulant & $\mathrm{IC}_{50} \sim 2-70 \mu \mathrm{M}$ & All \\
\hline Diarylamidines & Anti-parasitic & $\mathrm{IC}_{50} \sim 0.3-38 \mu \mathrm{M}$ & All \\
\hline Chloroquine & Anti-malaria & $\mathrm{IC}_{50} \sim 600 \mu \mathrm{M}$ & ASIC1a \\
\hline
\end{tabular}


Table 2

\begin{tabular}{|c|c|c|c|}
\hline Endogenous modulators & $\begin{array}{l}\text { Pharmacological/ } \\
\text { Therapeutic class }\end{array}$ & $\begin{array}{l}\text { Effective } \\
\text { concentration range }\end{array}$ & $\begin{array}{l}\text { ASIC channels } \\
\text { involved }\end{array}$ \\
\hline Agmatine, arcaine & Polyamines (GMQ-related) & $\mathrm{EC}_{50} \sim 1-10 \mathrm{mM}$ & ASIC3, ASIC3+1b \\
\hline Spermine & Polyamines & $\mathrm{EC}_{50} \sim 495 \mu \mathrm{M}$ & $\begin{array}{l}\text { ASIC1a, ASIC1b, } \\
\text { ASIC1a+2a }\end{array}$ \\
\hline $\mathrm{Cu}^{2+}, \mathrm{Pb}^{2+}, \mathrm{Ni}^{2+}, \mathrm{Cd}^{2+}, \mathrm{Gd}^{3+}$ & Cations & $\mu \mathrm{M}$ to $\mathrm{mM}$ range & All \\
\hline $\mathrm{Ca}^{2+}, \mathrm{Mg}^{2+}$ & Cations & $\mathrm{IC}_{50} \sim 2-10 \mathrm{mM}$ & All \\
\hline $\mathrm{Zn}^{2+}$ & Cations & $\begin{array}{l}\mathrm{EC}_{50} \sim 120 \mu \mathrm{M} \\
\mathrm{IC}_{50} \sim 10 \mathrm{nM} \\
\mathrm{IC}_{50} \sim 26-61 \mu \mathrm{M}\end{array}$ & $\begin{array}{l}\text { ASIC2a-containing } \\
\text { ASIC1a,ASIC1a+2a } \\
\text { ASIC1b, ASIC3 }\end{array}$ \\
\hline $\mathrm{NH4}^{+}$ & Cations & $1-10 \mathrm{mM}$ range & ASIC1a \\
\hline $\begin{array}{l}\text { FMRFamide and RFamide- } \\
\text { related peptides }\end{array}$ & Neuropeptides & $\mathrm{EC}_{50} \sim 10-50 \mu \mathrm{M}$ & $\begin{array}{l}\text { ASIC3, ASIC1a, } \\
\text { ASIC1b }\end{array}$ \\
\hline Dynorphins & Opioid neuropeptides & $\mathrm{EC}_{50} \sim 26-33 \mathrm{nM}$ & ASIC1a, ASIC1b \\
\hline Serotonine & Inflammatory mediator & $\mathrm{EC}_{50} \sim 41 \mu \mathrm{M}$ & ASIC3 \\
\hline $\begin{array}{l}\text { Arachidonic acid (AA), } \\
\text { anandamide }\end{array}$ & $\begin{array}{l}\text { Inflammatory mediator, } \\
\text { cannabinoid }\end{array}$ & $1-10 \mu \mathrm{M}$ range & All \\
\hline Nitric oxide (NO donors) & $\begin{array}{l}\text { Inflammatory/ischemia } \\
\text { mediator }\end{array}$ & $\begin{array}{l}\text { Potentiation } \\
\text { (NO donors: } 10- \\
100 \mu \mathrm{M})\end{array}$ & All \\
\hline
\end{tabular}


Table 3

\begin{tabular}{|c|c|c|c|}
\hline $\begin{array}{l}\text { Natural } \\
\text { compounds }\end{array}$ & $\begin{array}{l}\text { Pharmacological/ } \\
\text { Therapeutic class }\end{array}$ & $\begin{array}{l}\text { Effective } \\
\text { concentration range }\end{array}$ & ASIC channels involved \\
\hline Sevanol & Lignan from thyme & $\mathrm{IC}_{50} \sim 0.3-1.8 \mathrm{mM}$ & ASIC3, ASIC1a \\
\hline Gastrodin & Vegetal compound & $\mathrm{IC}_{50} \sim 0.2 \mu \mathrm{M}$ & $\begin{array}{l}\text { Native channels in sensory } \\
\text { neurons }\end{array}$ \\
\hline Chlorogenic acid & Vegetal polyphenol & $\mathrm{IC}_{50} \sim 0.2 \mu \mathrm{M}$ & $\begin{array}{l}\text { Native channels in sensory } \\
\text { neurons }\end{array}$ \\
\hline Thallassiolin B & Vegetal flavonoid & $\mathrm{IC}_{50} \sim 27 \mu \mathrm{M}$ & $\begin{array}{l}\text { Native channels in sensory } \\
\text { neurons }\end{array}$ \\
\hline Puerarin & Vegetal flavonoid & $\mathrm{IC}_{50} \sim 9-38 \mu \mathrm{M}$ & $\begin{array}{l}\text { Native ASIC and ASIC1a } \\
\text { currents in hippocampal neurons }\end{array}$ \\
\hline Paeoniflorin & Vegetal compound & $\mathrm{IC}_{50} \sim 5 \mu \mathrm{M}$ & $\begin{array}{l}\text { Native ASIC1a channels of PC12 } \\
\text { cell line }\end{array}$ \\
\hline PcTx1 & $\begin{array}{l}\text { Spider peptide toxin } \\
\text { (Psalmopoeus } \\
\text { cambridgei) }\end{array}$ & $\begin{array}{l}\mathrm{IC}_{50} \sim 0.4-4 \mathrm{nM} \\
100-190 \mathrm{nM} \text { range }\end{array}$ & $\begin{array}{l}\text { ASIC1a, ASIC1a+2b } \\
\text { ASIC1b, cASIC1 }\end{array}$ \\
\hline APETx2 & $\begin{array}{l}\text { Sea anemone peptide } \\
\text { toxin (Anthopleura } \\
\text { elegantissima) }\end{array}$ & $\mathrm{IC}_{50} \sim 37 \mathrm{nM}-2 \mu \mathrm{M}$ & ASIC3, ASIC3+1a/b, ASIC3/2b \\
\hline MitTx & $\begin{array}{l}\text { Snake toxin (Micrurus } \\
\text { tener tener) }\end{array}$ & $\mathrm{EC}_{50}: 9-830 \mathrm{nM}$ & $\begin{array}{l}\text { All, but strongest effect on } \\
\text { ASIC1-containing channels }\end{array}$ \\
\hline Mambalgins & $\begin{array}{l}\text { Snake peptide toxins } \\
\text { (Dendroaspis polylepis } \\
\text { polylepis, Dendroaspis } \\
\text { angusticeps) }\end{array}$ & $\mathrm{IC}_{50} \sim 11-250 \mathrm{nM}$ & $\begin{array}{l}\text { ASIC1a, ASIC } 1 b, \\
\text { ASIC } 1 a+2 a / 2 b, \text { ASIC } 1 a+1 b\end{array}$ \\
\hline Ugr 9-1 & $\begin{array}{l}\text { Sea anemone peptide } \\
\text { toxin (Urticina } \\
\text { grebelnyi) }\end{array}$ & $\mathrm{IC}_{50} \sim 1.5-10 \mu \mathrm{M}$ & Human ASIC3 \\
\hline PherTx1 & $\begin{array}{l}\text { Sea anemone peptide } \\
\text { toxin (Phymanthus } \\
\text { crucifer) }\end{array}$ & $\mathrm{IC}_{50} \sim 100 \mathrm{nM}$ & $\begin{array}{l}\text { Native channels in sensory } \\
\text { neurons }\end{array}$ \\
\hline
\end{tabular}

